\title{
Bi-Directional Mutual Energy Trade between Smart Grid and Energy Districts Using Renewable Energy Credits
}

\author{
Sana Rehman ${ }^{1}\left(\mathbb{D}\right.$, Bilal Khan ${ }^{1} \mathbb{D}$, Jawad Arif ${ }^{2} \mathbb{D}$, Zahid Ullah ${ }^{3, *} \mathbb{D}$, Abdullah J. Aljuhani ${ }^{4,5}$, Ahmad Alhindi ${ }^{6}$ \\ and Sahibzada M. Ali ${ }^{1}$
}

1 Department of Electrical \& Computer Engineering, Abbottabad Campus, COMSATS University Islamabad, Abbottabad 22060, Pakistan; sana.rehman@outlook.com (S.R.); bilalkhan@cuiatd.edu.pk (B.K.); hallianali@cuiatd.edu.pk (S.M.A.)

2 School of Electrical Engineering \& Computer Science (SEECS), National University of Sciences \& Technology (NUST), Islamabad 44000, Pakistan; jawad.arif@seecs.nust.edu.pk

3 Department of Electrical Engineering, Sialkot Campus, University of Management and Technology Lahore, Sialkot 51310, Pakistan

4 Department of Electrical and Computer Engineering, King Abdulaziz University, Jeddah 21589, Saudi Arabia; ajaljohani@kau.edu.sa

5 Center of Excellence in Intelligent Engineering Systems, King Abdulaziz University, Jeddah 21589, Saudi Arabia

6 Department of Computer Science, Umm Al-Qura University, Makkah 24381, Saudi Arabia; ahhindi@uqu.edu.sa

* Correspondence: zahid.ullah@skt.umt.edu.pk; Tel.: +92-3339226162

check for updates

Citation: Rehman, S.; Khan, B.; Arif, J.; Ullah, Z.; Aljuhani, A.J.; Alhindi, A.; Ali, S.M. Bi-Directional Mutual Energy Trade between Smart Grid and Energy Districts Using Renewable Energy Credits. Sensors 2021, 21, 3088. https://doi.org/ $10.3390 / \mathrm{s} 21093088$

Academic Editor: Claudia Daniela Antal

Received: 8 March 2021

Accepted: 22 April 2021

Published: 29 April 2021

Publisher's Note: MDPI stays neutral with regard to jurisdictional claims in published maps and institutional affiliations.

Copyright: (c) 2021 by the authors. Licensee MDPI, Basel, Switzerland. This article is an open access article distributed under the terms and conditions of the Creative Commons Attribution (CC BY) license (https:/ / creativecommons.org/licenses/by/ $4.0 /)$.

\begin{abstract}
A central authority, in a conventional centralized energy trading market, superintends energy and financial transactions. The central authority manages and controls transparent energy trading between producer and consumer, imposes a penalty in case of contract violation, and disburses numerous rewards. However, the management and control through the third party pose a significant threat to the security and privacy of consumers'/producers' (participants) profiles. The energy transactions between participants involving central authority utilize users' time, money, and impose a computational burden over the central controlling authority. The Blockchain-based decentralized energy transaction concept, bypassing the central authority, is proposed in Smart Grid (SG) by researchers. Blockchain technology braces the concept of Peer-to-Peer (P2P) energy transactions. This work encompasses the SolarCoin-based digital currency blockchain model for SG incorporating RE. Energy transactions from Prosumer (P) to Prosumer, Energy District to Energy District, and Energy District to SG are thoroughly investigated and analyzed in this work. A robust demand-side optimized model is proposed using Genetic Algorithm (GA) and Particle Swarm Optimization (PSO) to maximize Prosumer Energy Surplus (PES), Grid revenue (GR), percentage energy transactions accomplished, and decreased Prosumer Energy Cost (PEC). Real-time averaged energy data of Australia are employed, and a piece-wise energy price mechanism is implemented in this work. The graphical analysis and tabular statistics manifest the efficacy of the proposed model.
\end{abstract}

Keywords: blockchain; peer-to-peer; Solar Coin; energy transactions; energy districts; central authority

\section{Introduction}

Smart Grid (SG) has changed the way electricity is generated and consumed due to the adoption of the: (a) Advanced computational platform, (b) bi-directional communication of energy, (c) satisfying consumers need through reduced energy cost, and (d) automated, smart, secure network [1]. Energy Districts (EDs) permit small-scale Renewable Energy (RE) consumers and prosumers to trade energy locally [2], an evolving concept of environmentfriendly energy transfer. 
In conventional centralized energy systems, a central authority manages the energy transfer between consumers and prosumers. The central authority is responsible for supervising agreements and accomplishing transparent trading among participants [3]. However, the outlook of energy with the concept of prosumers accompanied with SG is complicated and challenging [4]. The intermittent RE resources demand for storage options to store surplus energy within SG. Therefore, the most important feature of transportation electrification is the Vehicle to Grid (V2G) concept that store the surplus energy and ensure the provision of surplus energy to SG during high load demand. The storage capability of V2G enhances the utilization of renewable energy sources within EDs [5,6]. The nonlinear and stochastic data within SG demands for advanced machine learning methods. Machine learning is an efficient tool to design energy management model for bidirectional energy and data flow between SG and ED [7]. The complex energy future with the need of integrating more and more RE in the power grid cannot be effectively managed through the conventional centralized system; thus, an alternative decentralized market approach is required.

In a traditional centralized network, more time and money of consumers are wasted involving a third party. The consumers encounter high transaction and management costs and have no direct access to the energy market [8]. The critical centralized architecture results in a computational burden on central authority and is greatly at threat of single-point failure [9]. The challenges associated with the conventional centralized energy network can be addressed through a decentralized approach surpassing the central authority. Blockchain technology is a widely emerging decentralized concept. Blockchain provides a platform for consumers and prosumers to buy and sell energy in a peer-to-peer (P2P) fashion [10] directly with each other and with the SG, bypassing the third party. P2P energy transactions reduce the management and transaction cost and permit consumers to have direct access to the energy market. Due to its decentralized nature blockchain is immune to a single-point failure.

The cost of running decentralized networks and mining cryptocurrencies requires a tremendous amount of energy resulting in an expensive decentralized blockchain network. The high cost of mining cryptocurrencies restricts the blockchain network to the moneyed community. Given the aforementioned issues incurred in decentralized blockchain networks, advance research is focusing on a cryptocurrency that assists a cost-effective network [11]. SolarCoin (SLR)-based blockchain is an evolving platform that addresses the issue of high energy consumption of another cryptocurrencies-based blockchain [12]. A cost-effective SLR blockchain network lays out an equal opportunity platform. Any person owning some SLR stakes is invited to join the blockchain network. Besides cracking the energy consumption problem, SLR encourages the transition from fossil fuel to clean green energy. Small or large-scale solar energy producers registered with Solar Coin Foundation (SCF) earns one SLR as a free incentive at the rate of one MW produced. Encouraging the users to install and rely on solar panels rather than the conventional fossil fuel energy method, through disbursing one SLR for each MWh as a free reward, is contributing towards a carbon-free environment. SLRs can be exercised for any purpose or can be converted to fiat currency [13].

Extensive research works have been dedicated to blockchain technology over the last few years [8-23]. Authors in [14] proposed IBM HyperLedger Fabric blockchain-based P2P crowdsourced energy model. Authors in [15] presented demand-side management permitting users to reduce their electricity bill through effective day-ahead scheduling of energy consumption incorporating the blockchain technology. In [16], authors explored ongoing blockchain-based microgrid projects and came with the idea of establishing a blockchain-based microgrid. Authors in [8] came up with the architecture of solar energy production and distribution incorporating Smart Contracts to establish an energy exchange market. In [3], authors proposed the design and implementation of a Decentralized Transactive platform encompassing fault detection. Authors in [17] proposed the design 
and implementation of local energy markets on a private blockchain and evaluation of an economic market mechanism.

A case study incorporating implemented Ethereum-based Brooklyn Microgrid (BMG) was evaluated by researchers in [2]. Authors in [18] proposed a privacy-preserving blockchain-enabled trading model. The authors addressed the privacy protection of individuals on consortium blockchain-based energy trading systems through the introduction of a noise-based privacy-preserving approach. In [19], authors evaluated blockchain-based demand-response distributed energy management for SGs. Effective distributed management through the detection of energy unbalances and disbursement of rewards and penalties was implemented using Smart Contracts. Authors in [20] proposed the implementation of blockchain technology to empower Machine-to-Machine (M2M) interactions in a chemical industry based on a proof-of-concept. The employment of Smart Contracts to enhance the speed, security, and scalability of blockchain-based energy exchange was proposed by authors in [21]. Different blockchain solutions were tested on the Pacific Northwest National Lab (PNNL)'s transactive campus to investigate and reduce possible associated cyber risks.

Although the above-mentioned research works successfully explored and implemented the characteristics and applications of blockchain technology in the energy market and SG, they lack in dispensing (a) the SLR blockchain-based Mutual Energy Trade Model (METM) incorporating demand-side management, (b) the evaluation of optimized energy transactions accomplished in a blockchain network considering seasonal variations, and (c) the implementation of energy transactions between prosumers, consumers, and multi-EDs based on SLR blockchain. Moreover, free SLRs disbursement as an incentive for Solar Energy Prosumers was not incorporated in previous works.

Significant contributions of this work based on the previous-mentioned issues are:

- SLR blockchain-based energy trade model is designed and analyzed that deploys Smart Contracts to empower mutual energy transactions between Prosumer and Consumer, Prosumer and Prosumer, multiple EDs, and between ED and SG. Three EDs are considered in this work with each ED comprising of N-consumers and Nprosumers. EDs are interfaced with SG as ED1 and ED2 are Solar Energy Districts and ED3 is Wind Energy District.

- A demand-side multi-objective optimization model is implemented. The Australianbased piece-wise real-time pricing scheme is considered. Price-based incentives are considered for prosumers to achieve the objectives of maximizing Prosumer Energy Surplus (PES), Grid Revenue (GR), percentage energy transactions accomplished, and minimization of Prosumer Energy Cost (PEC).

- Incentives coupled with SLR blockchain are considered for Solar Energy Prosumers. The performance of the proposed model is evaluated using a Genetic Algorithm and Particle Swarm Optimization considering seasonal variations. In-depth tabular and graphical comparison of GA optimized results and PSO is critically analyzed.

Table 1 summarizes the comparative analysis of selected research work conducted on blockchain technology. Table 1 also highlights the contributions of this work compared to existing research work. In Table $1, " \checkmark$ " represents the presence of the attributes and " $\boldsymbol{X}$ " represents the absence of the attributes.

The rest of the paper is organized as follows. Section 2 presents the proposed SLR blockchain-based METM. A blockchain-based optimization model is discussed in Section 3. Section 4 covers the performance evaluation accompanied by the data analysis, seasonal variations, blockchain implementation, and tabular statistics. The paper concludes with a summary and future directions in Section 5 . 
Table 1. Literature Review

\begin{tabular}{|c|c|c|c|c|c|c|c|c|}
\hline Ref. & DSM & BC & SLR-BC & SLRD & O-PEC & O-PES & O-GR & O-ET \\
\hline [2] & $x$ & $\checkmark$ & $x$ & $x$ & $x$ & $x$ & $x$ & $x$ \\
\hline [3] & $x$ & $\checkmark$ & $x$ & $x$ & $x$ & $x$ & $x$ & $x$ \\
\hline [5] & $x$ & $\checkmark$ & $x$ & $x$ & $x$ & $x$ & $x$ & $x$ \\
\hline [11] & $x$ & $\checkmark$ & $x$ & $x$ & $x$ & $x$ & $x$ & $x$ \\
\hline [12] & $\checkmark$ & $\checkmark$ & $x$ & $x$ & $\checkmark$ & $x$ & $x$ & $\checkmark$ \\
\hline [13] & $x$ & $\checkmark$ & $x$ & $x$ & $x$ & $x$ & $x$ & $x$ \\
\hline [14] & $\checkmark$ & $\checkmark$ & $x$ & $x$ & $\checkmark$ & $x$ & $x$ & $\checkmark$ \\
\hline [15] & $x$ & $\checkmark$ & $x$ & $x$ & $x$ & $x$ & $x$ & $x$ \\
\hline [16] & $\checkmark$ & $\checkmark$ & $x$ & $x$ & $\checkmark$ & $x$ & $x$ & $\checkmark$ \\
\hline [17] & $x$ & $\checkmark$ & $x$ & $x$ & $x$ & $x$ & $x$ & $x$ \\
\hline [18] & $x$ & $\checkmark$ & $x$ & $x$ & $x$ & $x$ & $x$ & $x$ \\
\hline TW & $\checkmark$ & $\checkmark$ & $\checkmark$ & $\checkmark$ & $\checkmark$ & $\checkmark$ & $\checkmark$ & $\checkmark$ \\
\hline
\end{tabular}

Abbreviations: DSM: Demand-side Management; BC: Blockchain; SLR-BC: SolarCoin Blockchain; SLRD: SolarCoin Disbursement; O-PEC: Optimized Prosumer Energy Cost; O-PES: Optimized Prosumer Energy Surplus; O-GR; Optimized Grid Revenue; O-ET: Optimized Energy Transactions; TW: This Work.

\section{SolarCoin (SLR) Blockchain-Based Mutual Energy Trade Model (METM)}

This section presents the proposed SLR Blockchain-based METM. The pricing mechanism and mutual energy contracts employed in this work are also explicated in this section.

\subsection{System Model}

Figure 1 presents the proposed blockchain-based energy model, which comprises three distributed EDs: Two Solar EDs and a wind ED. Each Solar ED includes N-consumers and N-Solar Energy Prosumers (SEPs). Similarly, Wind ED incorporates N-Wind Energy Prosumers (WEPs) accompanied by N-consumers. The energy demand of three EDs cannot be met alone through RE and are interfaced with SG. Three EDs also support SG during peak hours. The energy transactions between multiple prosumers, consumers, EDs, and SG are carried on a P2P SLR blockchain platform, as shown in Figure 1.

Transactions executed on a digital network eliminating the third party contribute to a cost-effective system. SEPs and WEPs produce energy, satisfy their load requirements, and share the surplus, unused energy with neighboring consumers. Blockchain permits prosumers and consumers to trade energy transparently and securely without relying on the grid. Consumers and Prosumers on the network can buy energy at a reduced cost and are paid for selling excess energy to neighboring users and the grid. Participants on the blockchain network are referred to as nodes. SLR is exchanged among the nodes of the network as a result of energy transactions.

In Figure 1, SEPs and WEPs update their status on the network claiming to sell energy. Consumers wanting to buy energy put requests on the network.

Prosumers and consumers on the blockchain network undertake an agreement under the umbrella of a contract without the need of trusting each other. The nodes must fulfill contract conditions to carry out energy transactions. The contract will be executed automatically after the conditions are satisfied. The system (a) connects prosumer and consumer on the network and scrutinizes (b) energy availability according to consumer's request, (c) Consumer's balance, and SLRs at hand. On satisfactory execution of the contract, the transaction record is dispensed to each node of the network for verification. After verification, the transaction is accomplished, and a block of the transaction is added to the chain of the network. 


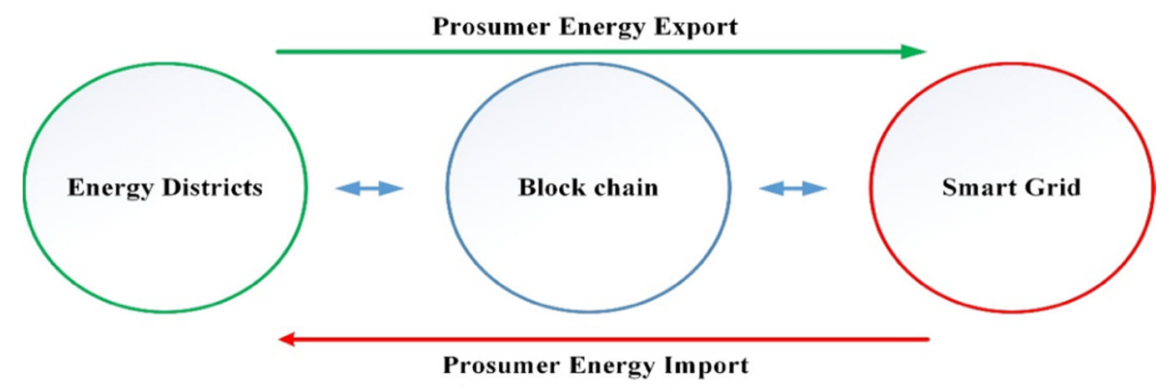

(a)

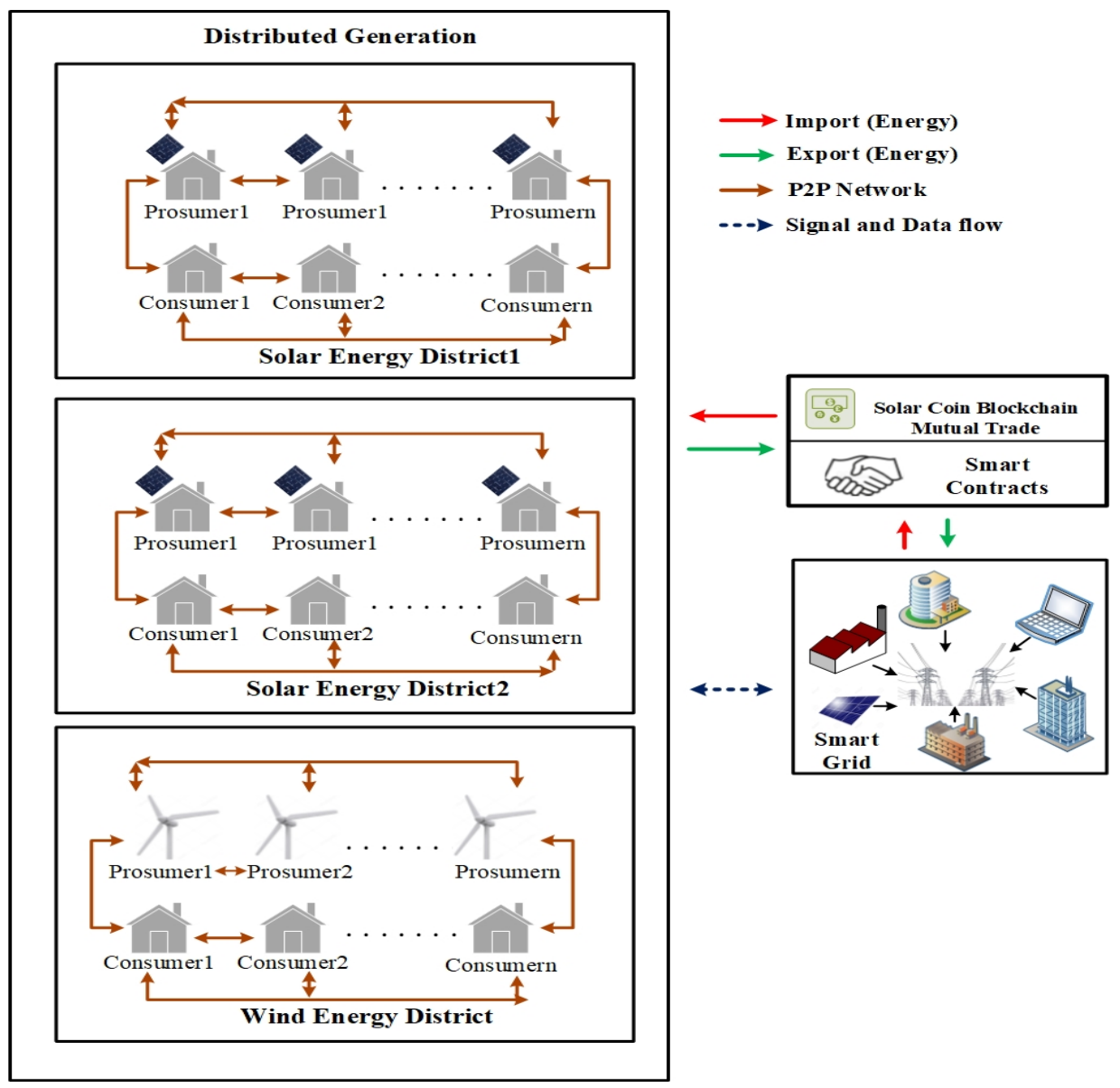

(b)

Figure 1. (a) Blockchain-based bi-directional METM, (b) SLR Blockchain-based bi-directional METM.

\subsection{Pricing Mechanism}

The Queensland, Australia-based piece-wise energy price mechanism is implemented in this work. In this pricing mechanism, consumers are charged according to (a) the amount of energy utilized and (b) the day and time of energy utilization. Consumers encounter high energy utilization rates during peak hours. Low energy utilization rates are offered during off-peak hours. No peak hour utilization rates are charged on weekends [22]. The pricing mechanism incorporated in this work is illustrated in Table 2. In Queensland, on 26 February 2020, peak and off-peak utilization rates charged were \$325.87/MWhr and \$151.73/MWhr, respectively [23]. One USD (United States Dollar) is equal to 34.06690740614567 SLRs as of 23 February 2021 [24]. 
Table 2. The implemented energy price mechanism.

\begin{tabular}{|c|c|c|c|}
\hline Time of Utilization & $\begin{array}{l}\text { Amount of Energy } \\
\text { Consumed (MWhr) }\end{array}$ & $\begin{array}{l}\text { Energy Price in } \\
\text { Dollars (\$/MWhr) }\end{array}$ & $\begin{array}{l}\text { Energy Price in SLRs } \\
\text { (SLR/MWhr) }\end{array}$ \\
\hline Off-peak & 0.2 & $151.73 \times 0.2=30.3$ & $30.3 \times 94.0733=2854$ \\
\hline On-peak & 0.2 & $325.87 \times 0.2=65.1$ & $65.1 \times 94.0733=6131$ \\
\hline
\end{tabular}

The proposed blockchain-based EDs offer consumers lower energy prices than the conventional grid. Prosumers rate their surplus energy 10 percent lower than rates offered by the traditional grid. Energy exported to SG is 10 percent higher than the normalized rates. Table 3 demonstrates the pricing mechanism exercised on the proposed blockchain platform.

Table 3. Implemented price mechanism in a blockchain.

\begin{tabular}{cccc}
\hline Time of Utilization & $\begin{array}{c}\text { Energy Price in } \\
\text { Consumed (MWhr) }\end{array}$ & $\begin{array}{c}\text { Dollars (\$/MWhr, 10 } \\
\text { Percent Discounted } \\
\text { Rates) }\end{array}$ & $\begin{array}{c}\text { Energy Price in SLRs } \\
\text { (SLR/MWhr) }\end{array}$ \\
\hline Off-peak & 0.2 & 27.2 & 2556 \\
On-peak & 0.2 & 58.5 & 5517 \\
\hline
\end{tabular}

\subsection{Mutual Energy Contract (MEC)}

The nodes of the network agree upon and sign a desired and flexible mutual energy contract to carry out energy transactions without involving a third party. This energy contract across the blockchain platform is referred to as Smart Contract (SC), which is an enforced agreement holding certain rules that need to be followed by every node of the network. SC empowers transparent and trusted energy transactions among nodes of the network and behaves as the controlling entity of a decentralized network [19]. SC is immutable, self-executing, written in the form of code, and is stored on the blockchain [25].

Prosumer mode: Whenever the energy produced by a participant of the network is more than the energy demand, participants announce themselves as prosumers to sell extra, unused energy to grid or neighboring users.

$$
\text { Prosumer mode } \approx P_{\text {gen }}{ }^{h}>P_{\text {dem }}{ }^{h}
$$

where $P_{\text {gen }}{ }^{h}$ and $P_{\text {dem }}{ }^{h}$ refer to prosumer's energy generation and demand at hour $h$, respectively.

Consumer mode: Whenever the energy produced by the participants is not enough to satisfy their energy demand, participants announce themselves as consumers and put an energy request on the network.

$$
\text { Consumer mode } \approx P_{\text {gen }}{ }^{h}<P_{\text {dem }}{ }^{h}
$$

Prosumer energy rate: On the blockchain network, prosumers sell energy at a rate 10 percent less than the normalized rates. Consumers buy energy from prosumers on the network at a price offered less than the traditional grid. Prosumers export energy to SG at a rate 10 percent higher than the normalized rates.

$$
P_{P r}{ }^{h} \approx\left\{\begin{array}{c}
\text { for } C, 10 \%<P_{R}{ }^{h} \\
\text { for } S G, 10 \%>P_{R}{ }^{h}
\end{array}\right.
$$

where $P_{P r}{ }^{h}$ is the real-time energy Price (Pr) offered by the Prosumer (P) to Consumer (C) and SG in a blockchain network at hour $h . P_{R}{ }^{h}$ is the real-time energy price offered by the grid at hour $h$. 
Incentives: Solar energy prosumers are rewarded 1 SLR for each MW solar energy produced from the SCF [13].

Energy Transactions: In our proposed model, energy transactions are carried out in four different categories under SC.

(a) Prosumer-to-Consumer (P-C): On the digital blockchain network, prosumers share the information of their energy generation. Consumers reach the prosumer to satisfy load requirements, without relying on the grid.

$$
\sum_{h=1}^{H} C_{d e m}^{h} \leftarrow \sum_{h=1}^{H} P E S^{h}
$$

where $C_{d e m}{ }^{h}$ demonstrates the Consumer energy demand at hour $h, P E S^{h}$ refers to Prosumer Energy Surplus (PES) at hour $h$. Arrow indicates the $C$ energy demand satisfying through PES.

(b) Prosumer-to-Prosumer (P-P): Whenever the prosumers' energy produced from RE is not enough to meet their load requirements, prosumers import energy from other prosumers in an ED.

$$
\sum_{h=1}^{H} P_{1, \text { dem }}{ }^{h} \leftrightarrow \sum_{h=1}^{H} P_{2, \text { dem }}{ }^{h}
$$

where $P_{1, \mathrm{dem}}{ }^{h}, P_{2, \mathrm{dem}}{ }^{h}$ indicate the first and second Prosumer energy demand at hour $\mathrm{h}$, respectively. The arrow specifies mutual energy trade between two prosumers.

(c) Energy District-to-Energy District (ED-ED): An ED fulfills its load requirements from other ED at times of reduced energy generation from RE.

$$
\sum_{h=1}^{H} E D_{1, \text { dem }}{ }^{h} \leftrightarrow \sum_{h=1}^{H} E D_{2, d e m}{ }^{h}
$$

where $E D_{1, \text { dem }}{ }^{h}, E D_{2, \text { dem }}{ }^{h}$ points out the first $E D^{\prime}$ s and 2nd ED's energy demand at hour $h$, respectively.

(d) Energy District-to-Smart Grid (ED-SG): The bi-directional feature and addition of prosumer to SG is beneficial to both SG and prosumer. At times of minimum RE generation, EDs import deficient energy from SG, while at times of maximum RE production, EDs sell surplus and unused energy to SG and are incentivized with SLRs.

$$
\sum_{h=1}^{H} E D_{d e m}{ }^{h} \leftrightarrow \sum_{h=1}^{H} S G_{d e m}{ }^{h}
$$

where $S G_{d e m}{ }^{h}$ refers to Smart Grid's energy demand at hour $h$.

Constraints: The following constraints are encoded in our implemented SC.

(a) Prosumers and consumers must be connected on the blockchain network.

$$
\sum_{h=1}^{H} P_{c}{ }^{h}=\sum_{h=1}^{H} C_{c}{ }^{h}=1
$$

where $P_{c}{ }^{h}, C_{c}{ }^{h}$ in Equation (8) refers to prosumer and consumer connectivity in the blockchain network at hour $h$, respectively.

$$
\sum_{h=1}^{H} P E S^{h} \geq \sum_{h=1}^{H} C_{d e m}{ }^{h}
$$


(b) Prosumers must have enough surplus energy to satisfy the consumer's load requirement.

(c) The consumer must not be a defaulter (must have enough SLR to import energy).

$$
\sum_{h=1}^{H} \text { Caccount }^{h} \geq \sum_{h=1}^{H} P_{P r}{ }^{h}
$$

where Caccount ${ }^{h}$ demonstrates the consumer's account status at hour $h$ and $P_{P r}{ }^{h}$ refers to th ereal-time energy price offered by prosumer at hour $h$.

(d) Prosumer must sell energy at a reduced rate.

$$
\sum_{h=1}^{H} P_{P r}{ }^{h} \leq \sum_{h=1}^{H} P_{R}{ }^{h}
$$

where $P_{R}{ }^{h}$ in Equation (11) indicates the real-time energy price encounters by the consumer from the grid.

\section{Blockchain-Based Robust Optimization Model}

The advanced technical appliances contribute to an elevated consumers' energy consumption profile. The increased energy consumption overturns high energy costs. An effective Demand-Side Management (DSM) technique curtails the consumer's energy consumption and the energy cost incurred by the consumer is substantial. The bi-directional communication in SG assists for an effective DSM [26]. Moreover, it empowers RE prosumers to import surplus energy to neighboring users and the grid.

In this paper, the implemented pricing mechanism assists in the execution of DSM. Consumers are encouraged to shift their energy consumption pattern towards off-peak periods due to low energy prices offered during off-peak hours. The implementation of the DSM technique results in (a) reduced consumer's energy cost, (b) increased production of Prosumer Energy Surplus through maximum utilization of RES, and (c) increased Grid Revenue as a result of maximum RE import to the grid. The multi-objective optimization problem is solved using demand-response algorithms. The Genetic Algorithm (GA) Optimization and the Particle Swarm Optimization (PSO) algorithm are implemented in this work.

\subsection{Prosumer Energy Surplus (PES)}

The prosumer energy generated from solar or wind suffers from fluctuations. At times, the energy generated through RE exceeds the prosumer's energy demand, enabling prosumers to merchandise this excess energy with the neighboring user. This generated energy that outstrips prosumers' energy demand is referred to as Prosumer Energy Surplus (PES) [27].

$$
\text { PES }=P_{\text {gen }}-P_{\text {dem }}
$$

The system defined in this work maximizes the PES considering certain constraints. The optimization problem of PES is formulated as:

$$
\max \sum_{h=1}^{H}\left(P_{g e n}^{h}-P_{d e m}^{h}\right)
$$

Subject to:

$$
\begin{aligned}
& 0 \leq\left(P_{\text {gen }}^{h}\right) \leq\left(P_{\text {gen,max }}^{h}\right) \\
& 0 \leq\left(P_{d e m}^{h}\right) \leq\left(P_{\text {dem, } \max }^{h}\right)
\end{aligned}
$$


where $P_{g e n}^{h}$ refers to prosumers' energy generated from wind or solar at hour $h$ and $P_{d e m}^{h}$ speaks for prosumers' actual energy demand at hour $h . P_{\text {gen,max }}^{h}$ and $P_{\text {dem, max }}^{h}$ identifies the prosumers' maximum energy generation and demand, respectively. Equation (13) represents the objective function, and Equations (14) and (15) are inequality constraints of an optimization problem.

\subsection{Prosumer Energy Cost (PEC)}

The prosumer energy demand that exceeds wind- or solar-generated energy compels the prosumer to import this deficient energy from the grid or neighboring users to meet energy requirements. The imported energy cost incurred by the prosumer is referred to as Prosumer Energy Cost (PEC).

$$
P E C=P_{\text {dem }}-P_{\text {gen }}
$$

The presented model focuses on minimizing PEC through optimization of the prosumer energy demand. The mathematical formulation of the optimization problem for PEC is expressed as:

$$
\min \sum_{h=1}^{H} P_{R}^{h} *\left(P_{d e m}^{h}-P_{g e n}^{h}\right)
$$

Subject to:

$$
\begin{aligned}
& 0 \leq\left(P_{\text {gen }}^{h}\right) \leq\left(P_{\text {gen,max }}^{h}\right) \\
& 0 \leq\left(P_{\text {dem }}^{h}\right) \leq\left(P_{\text {dem, } \max }^{h}\right)
\end{aligned}
$$

where Equation (17) specifies the objective function of the presented optimization problem with Equations (18) and (19) acting as inequality constraints. $P_{R}^{h}$ refers to real-time energy price offered by the grid at hour $h$.

\subsection{Grid Revenue}

The PES exported to the grid results in an incentive for prosumers defined as Grid Revenue (GR), expressed as:

$$
\begin{gathered}
G R=\left(\left(P_{R} * E_{\text {impSG }}\right)+\left(\left(P_{R}-P_{n}\right)+P E S\right)\right) \\
\max \sum_{h=1}^{H}\left(\left(P_{R}^{h} * E_{\text {impSG }}^{h}\right)+\left(P E S^{h} *\left(P_{R}^{h}-P_{n}^{h}\right)\right)\right) \\
0 \leq\left(P_{\text {gen }}^{h}\right) \leq\left(P_{\text {gen,max }}^{h}\right)
\end{gathered}
$$

Subject to:

$$
0 \leq\left(P_{d e m}^{h}\right) \leq\left(P_{d e m, \max }^{h}\right)
$$

The proposed model emphasizes the maximization of GR. The optimization problem formulation for GR is illustrated in Equations (21)-(23). Equation (21) presents the objective function of the maximization problem while Equations (22) and (23) are inequality constraints of an optimization problem.

$P_{n}^{h}$ is the nominal price proposed to SG on account of prosumer energy export and $E_{i m p S G}^{h}$ is the energy imported from SG at hour $h$. 


\subsection{Prosumer Energy Surplus (PES) and Prosumer Energy Cost (PEC)}

This research work focuses on the comparative analysis of PES and PEC in one domain subjected to diverse weather fluctuations. The merged mathematical model for the minimization of PEC and maximization of PES is expressed as:

$$
\min \sum_{h=1}^{H} P_{R}^{h} *\left(P_{d e m}^{h}-P_{g e n}^{h}\right)-n * \max \sum_{h=1}^{H}\left(P_{g e n}^{h}-P_{d e m}^{h}\right)
$$

Subject to:

$$
\begin{gathered}
0 \leq\left(P_{\text {gen }}^{h}\right) \leq\left(P_{\text {gen,max }}^{h}\right) \\
0 \leq\left(P_{\text {dem }}^{h}\right) \leq\left(P_{\text {dem,max }}^{h}\right) \\
0 \leq\left(n^{h}\right) \leq(100)
\end{gathered}
$$

where $\eta$ is the weighting function.

\subsection{Optimization Algorithm}

This research work uses Particle Swarm Optimization (PSO) and Genetic Algorithm (GA) optimization algorithms for the minimization of PEC and maximization of PES, percentage energy transactions accomplished throughout the year, and GR.

Algorithms 1 and 2 solve the multi-objective optimization problem to carry out the objectives of increased PES, GR, and minimized PEC, respectively.

The layout of GA for the optimization of PEC, PES, and GR is presented as:

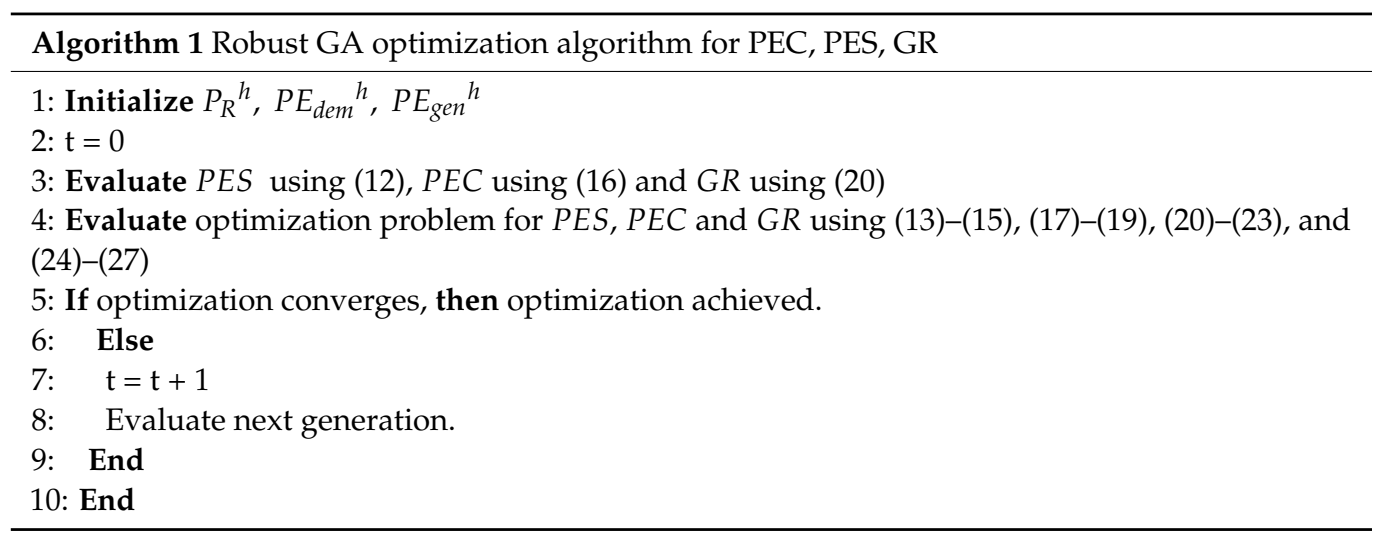

Algorithm 2 presents the layout of the PSO technique for PEC, PES, and GR.

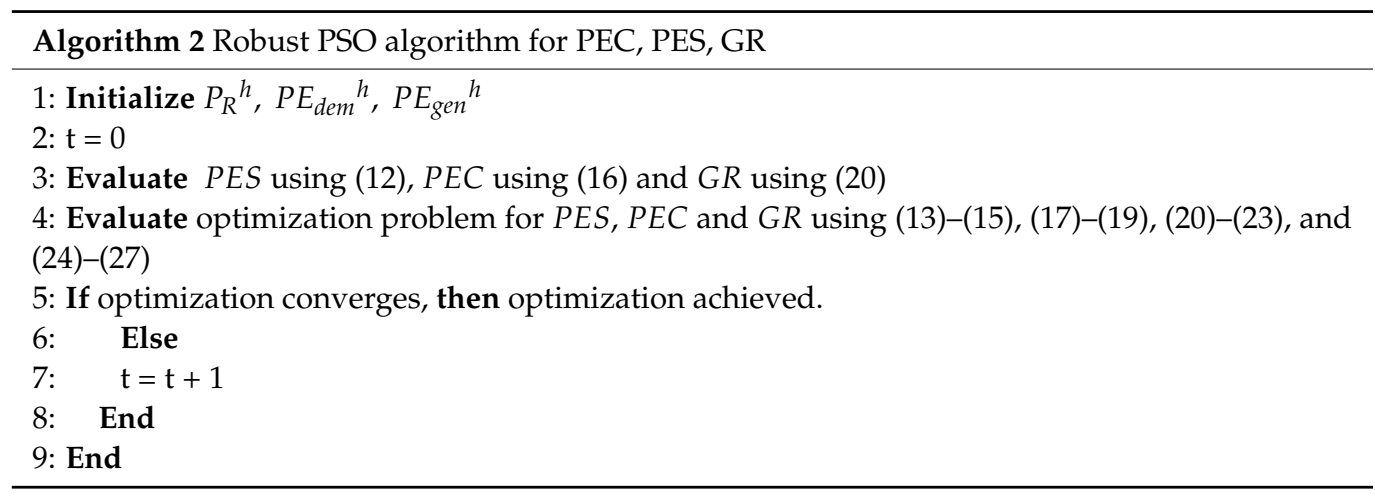

\subsection{Proposed Blockchain Optimization Model}

Robust demand-side optimization is considered to be a pivotal element in implementing blockchain-based energy transactions. This work aims at accomplishing maximum energy transactions among participants of the SLR blockchain network throughout 
the year. The mathematical formulation of the optimization problem is expressed in Equations (28)-(39), with Equations (28)-(31) acting as the objective function of the maximum optimization problem. Equations (32)-(35) and Equations (37)-(39) are inequality constraints of the optimization problem while Equation (36) presents equality constraints of the proposed optimization problem.

$$
\begin{aligned}
\max \left(\sum_{h=1}^{H} C_{\text {dem }}{ }^{h}\right. & \left.\leftarrow \sum_{h=1}^{H} P E S^{h}\right) \\
\max \left(\sum_{h=1}^{H} P_{1, \text { dem }}{ }^{h}\right. & \left.\leftrightarrow \sum_{h=1}^{H} P_{2, \text { dem }}{ }^{h}\right) \\
\max \left(\sum_{h=1}^{H} E D_{1, \text { dem }}{ }^{h}\right. & \left.\leftrightarrow \sum_{h=1}^{H} E D_{2, \text { dem }}{ }^{h}\right) \\
\max \left(\sum_{h=1}^{H} E D_{\text {dem }}{ }^{h}\right. & \left.\leftrightarrow \sum_{h=1}^{H} S G_{d e m}{ }^{h}\right)
\end{aligned}
$$

Subject to:

$$
\begin{gathered}
0 \leq\left(C_{\text {dem }}^{h}\right) \leq\left(C_{\text {dem, max }}^{h}\right) \\
0 \leq\left(P_{1, \text { dem }}^{h}\right) \leq\left(P_{1, \text { dem,max }}^{h}\right) \\
0 \leq\left(P_{2, \text { dem }}^{h}\right) \leq\left(P_{2, \text { dem,max }}^{h}\right) \\
0 \leq\left(E D_{1, \text { dem }}^{h}\right) \leq\left(E D_{2, \text { dem, max }}^{h}\right) \\
\sum_{h=1}^{H} P_{c}^{h}=\sum_{h=1}^{H} C_{c}^{h}=1 \\
\sum_{h=1}^{H} P E S^{h} \geq \sum_{h=1}^{H} C_{\text {dem }}{ }^{h} \\
\sum_{h=1}^{H} \text { Caccount }^{h} \geq \sum_{h=1}^{H} P_{P r}{ }^{h} \\
\sum_{h=1}^{H} P_{P r}{ }^{h} \leq \sum_{h=1}^{H} P_{R}{ }^{h}
\end{gathered}
$$

where $C_{d e m, \max }^{h}$ is the consumer's maximum energy demand at hour $h .\left(P_{1, \text { dem, max }}^{h}\right)$ represents the first prosumer's maximum energy demand and $\left(P_{2, \text { dem,max }}^{h}\right)$ illustrates the second prosumer's maximum energy demand at hour $h .\left(E D_{2, \text { dem, max }}^{h}\right)$ represents ED's maximum demand at hour $h$.

Energy transactions among multiple participants of the proposed model are accomplished utilizing Algorithms 3 and 4.

The layout of the energy transactions carried out among multiple prosumers, consumers, EDs, and SG is portrayed through the following algorithms: 

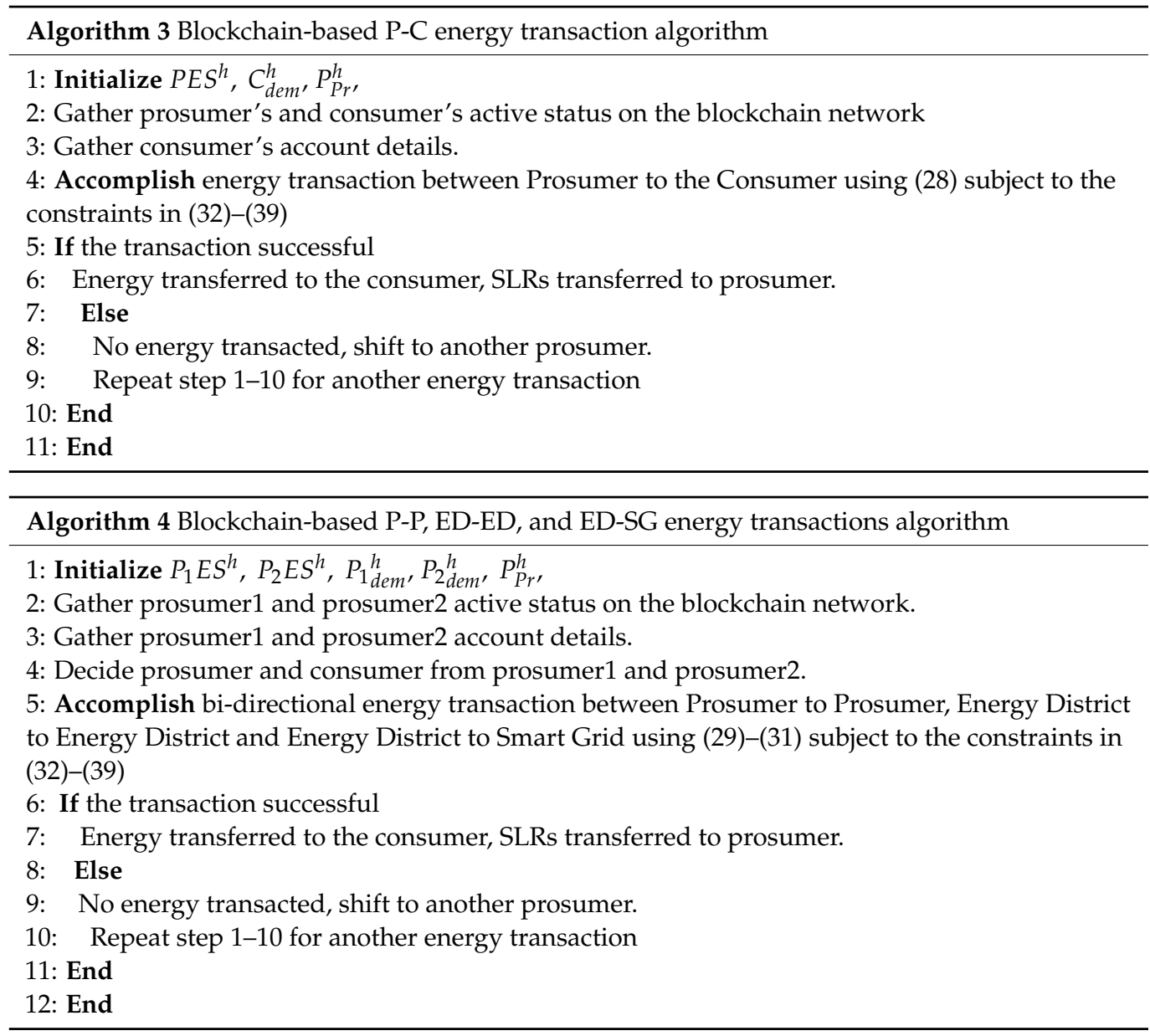

\section{Performance Evaluation}

This section arrays the implementation of SLR blockchain-based METM. An in-depth analysis accompanied by the detailed results of the proposed model is incorporated in this section.

\subsection{Data Analysis}

The proposed model in this article is evaluated regulating Australian-based case studies. The energy generation and consumption data profiles of one year from Queensland (Australia) are considered. For the simulation of each day, energy data of $24 \mathrm{~h}$ are considered. We have considered independent solar energy producers, and their energy profiles are taken from Queensland Live Solar Outputs [28]. Two onshore wind farms, Cooper Gap Wind Farm (COOPGWF1) and Mount Emerald Wind Farm (MEWF1), with the generating capacity of 452 and $180 \mathrm{MW}$, respectively, are considered. Their hourly energy generation data are extracted from Aneroid Energy [29]. The energy demand for Queensland and grid generation data are extracted from AEMO [30].

\subsection{Seasonal Variations}

In our presented case study, blockchain-based energy transactions and DSM are analyzed under the influence of four seasons i.e., Spring, Summer, Autumn, and Winter seasons.

\subsubsection{Spring Season}

Australian seasons come about at times opposite to the northern hemisphere. The Spring season is observed from September to November [31]. In Queensland, September and October are the months experiencing the best solar performance with 7.25 and 6.28 peak sun $h /$ day [32]. These months are considered as windier months of the year with an average 
wind speed exceeding $4.2 \mathrm{~m} / \mathrm{s}$ [33]. Prosumers have enough energy generation, and export surplus energy to neighboring users and the grid. Increased export and decreased import from the grid overturns reduced PEC. Figure 2 shows the unoptimized and optimized PEC, PES, and GR. ED1 and the month of October are considered for graphical analysis. The 9th, 14th, 23rd, 24th, and 29th of October have the maximum solar irradiance resulting in escalated solar energy generation and minimum PEC; while on the 4th, 10th, and 15th of October, minimum solar energy is produced, compelling the prosumer to import energy from the grid, resulting in an increased PEC. The figure demonstrates that the maximum solar energy is produced on the 9th, 14th, 23rd, 24th, and 29th of October due to increased solar radiation resulting in high PES. The minimum solar energy is generated on the 4th, 10th, and 15th of October leading to decreased PES. The maximum generation of PES on the 9th, 14th, 23rd, 24th, and 29th of October permits the prosumer to sell extra energy to the grid, paving the way for an escalated GR; while the minimum PES generation on the 4th, 10th, and 15th of October results in decreased GR.
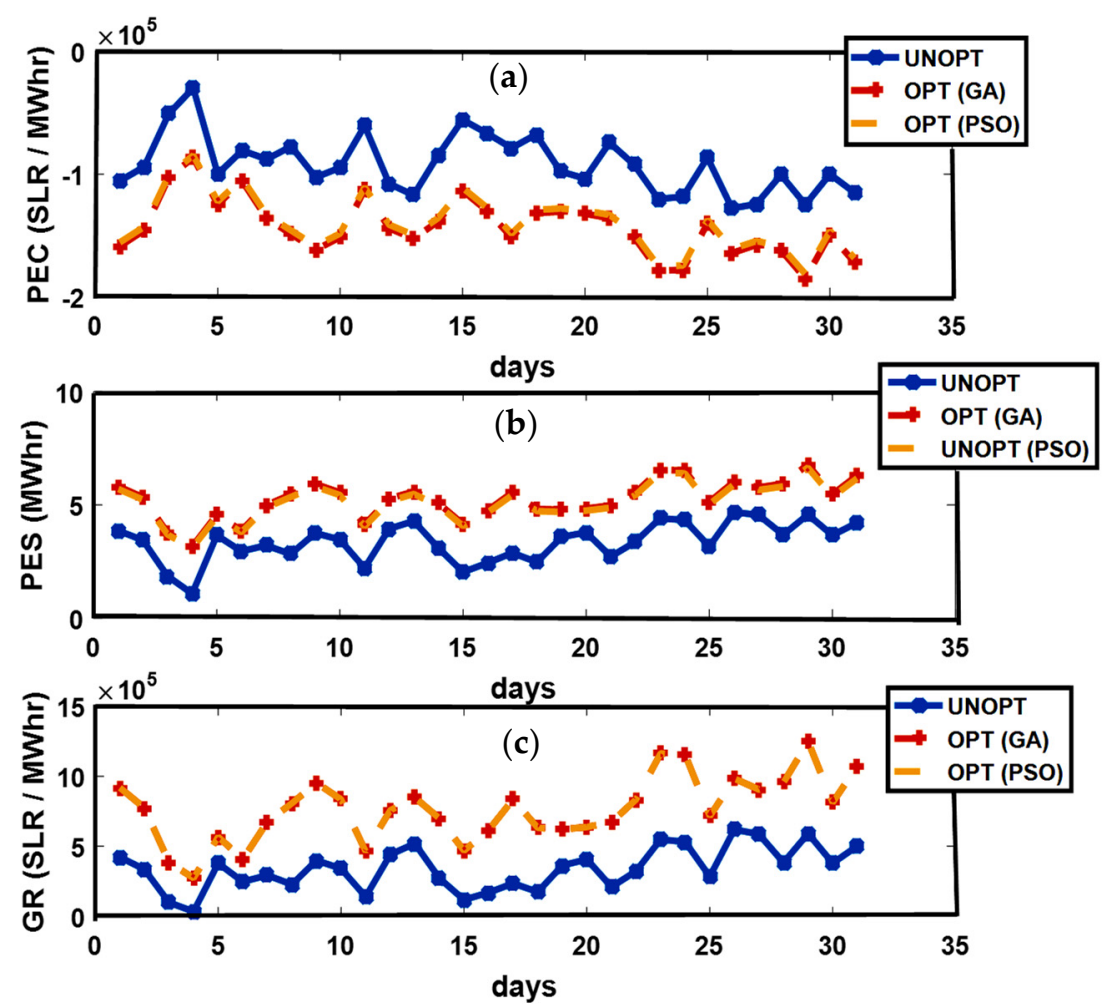

Figure 2. (a): Prosumer Energy Cost (PEC); (b): Prosumer Energy Surplus (PES); (c): Grid Revenue (GR).

The energy transactions between P-C, P-P, ED-ED, and ED-SG are presented in Figure 3. The optimized results outweigh the unoptimized results. GA and PSO maximize the PES and GR and minimize PEC. Similarly, more optimized energy transactions are performed than unoptimized transactions due to the maximization of PES. Due to the availability of surplus energy, ED imports surplus unused energy to SG, as shown in Figure 3. 


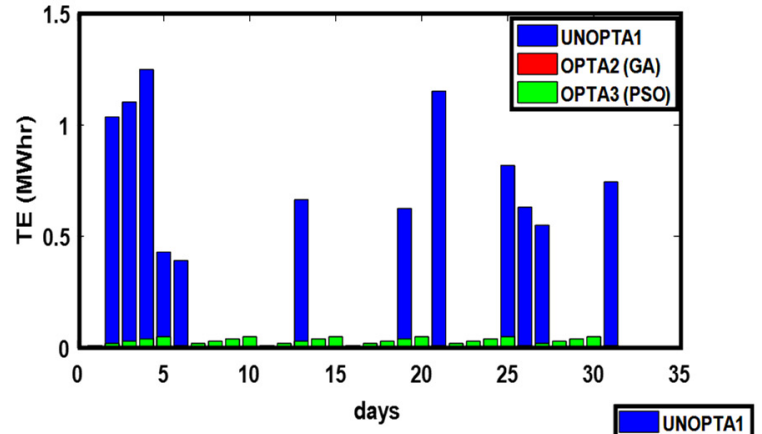

(a)

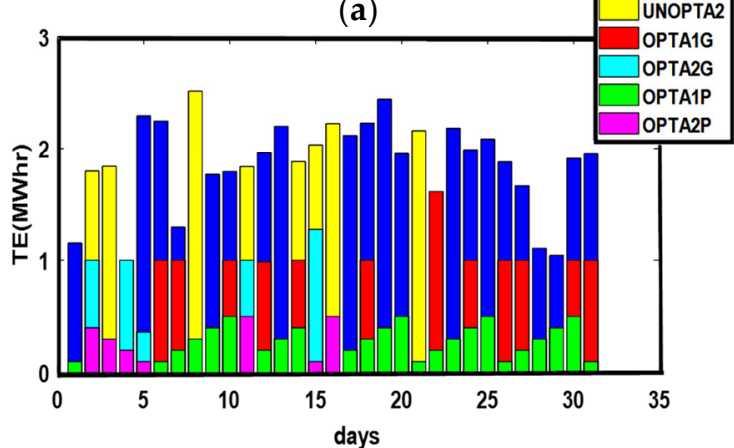

(c)

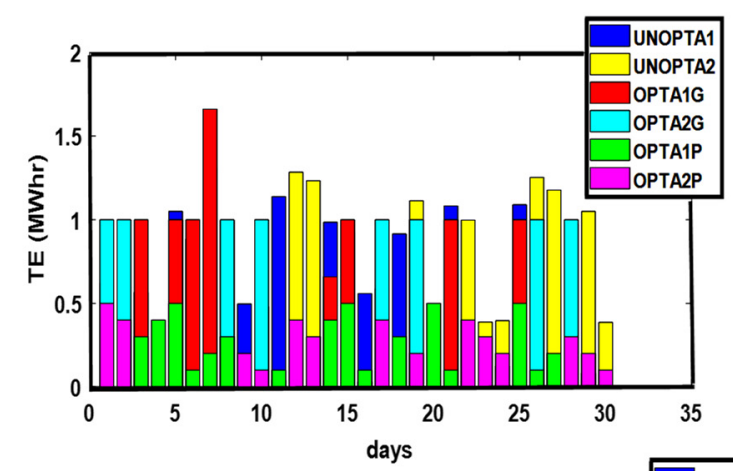

(b)

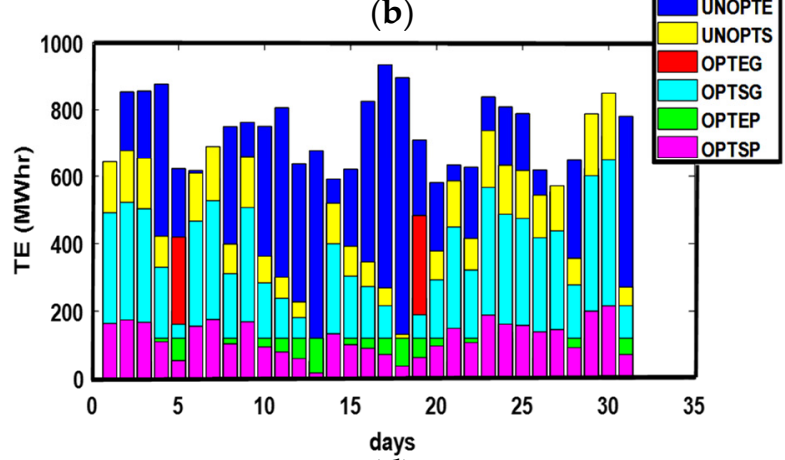

(d)

Figure 3. (a) P-C, (b) P-P, (c) ED-ED, and (d) ED-SG Energy Transactions. (a) TE: Transacted Energy, UNOPTA1: Unoptimized Consumer Energy, OPTA2 (GA): GA Optimized consumer energy, OPTA3 (PSO): PSO consumer energy; (b) UNOPTA1: Prosumer 1 Unoptimized transacted energy, UNOPTA2: Prosumer 2 Unoptimized transacted energy, OPTA1G: Prosumer 1 GA Optimized transacted energy, OPTA2G: Prosumer 2 GA Optimized transacted energy, OPTA1P: Prosumer 1 PSO transacted energy, OPTA2P: Prosumer 2 PSO transacted energy; (c) UNOPTA1: ED1 Unoptimized transacted energy, UNOPTA2: ED2 Unoptimized transacted energy, OPTA1G: ED1 GA Optimized transacted energy, OPTA2G: ED2 GA Optimized transacted energy, OPTA1P: ED1 PSO transacted energy, OPTA2P: ED2 PSO transacted energy; (d) UNOPTE: ED Unoptimized transacted energy, UNOPTS: SG Unoptimized transacted energy, OPTEG: ED GA Optimized transacted energy, OPTSG: SG GA Optimized transacted energy, OPTEP: ED PSO transacted energy, OPTSP: SG PSO transacted energy.

\subsubsection{Summer Season}

In Australia, the Summer season is observed from December to February. Average solar performance during the summer season is recorded as 6.22 peak sun $\mathrm{h} /$ day. The months in the Summer season are considered as the windier part of the year with an average wind speed of $4.2 \mathrm{~m} / \mathrm{s}$. February 26th is recorded as the windiest day of the year with an average wind speed of $4.5 \mathrm{~m} / \mathrm{s}$ [33]. Excellent solar irradiance and wind speed contribute to an increased PES and minimized PEC. Unoptimized and optimized PEC, PES, and GR are presented in Figure 4. Maximum PEC is observed on 10th, 15th, 20th, 23rd, and 31st of January while the 1st, 5th, 12th, 18th, 21st, and 30th of January flag the minimum PEC. Due to high solar irradiance observed on the 1st, 5th, 12th, 18th, 21st, and 30th of January, the maximum energy surplus is produced. On the 10th, 15th, 20th, 23rd, and 31st of January, the minimum energy surplus is produced. The maximum GR is marked on the 3rd of January while minimum GR is observed on the 10th, 15th, and 20th of January due to the minimum energy production. The energy transactions between P-C, P-P, ED-ED, and ED-SG are presented in Figure 5. 


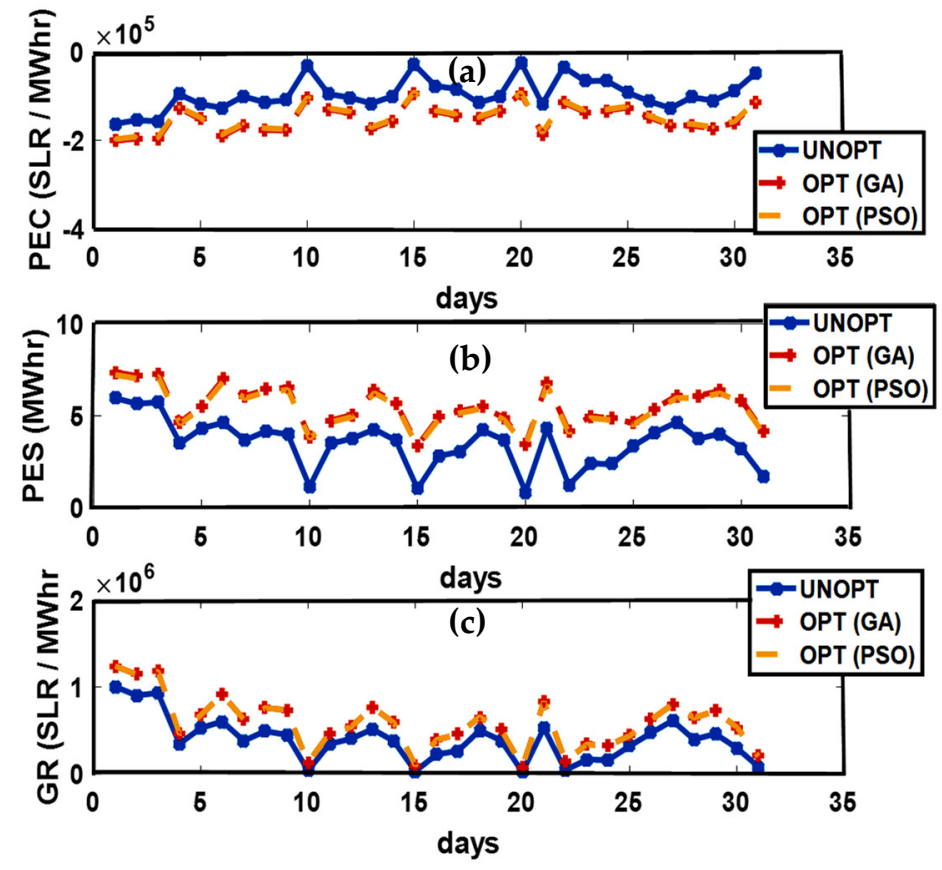

Figure 4. (a) Prosumer Energy Cost (PEC), (b) Prosumer Energy Surplus (PES), (c) Grid Revenue (GR).
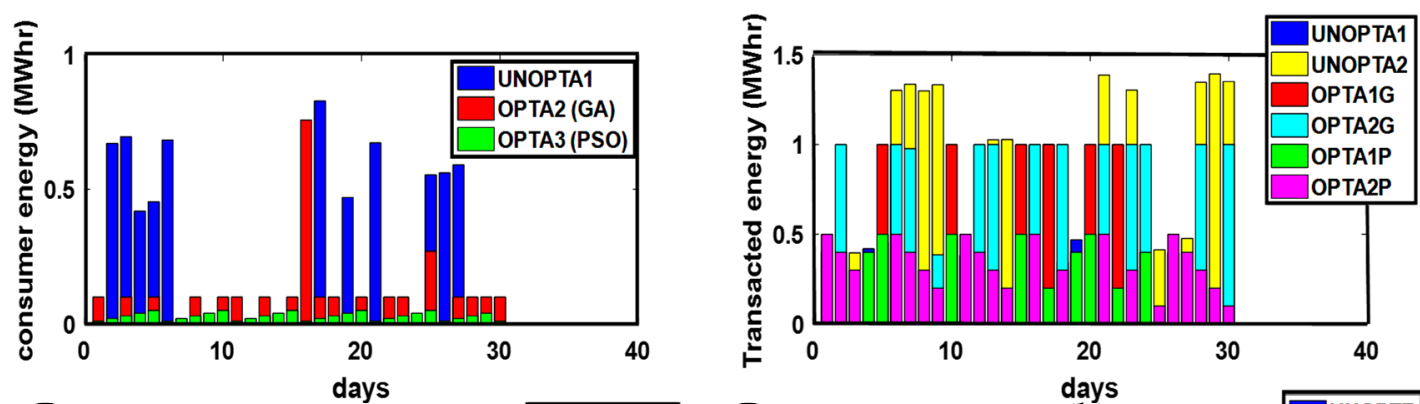

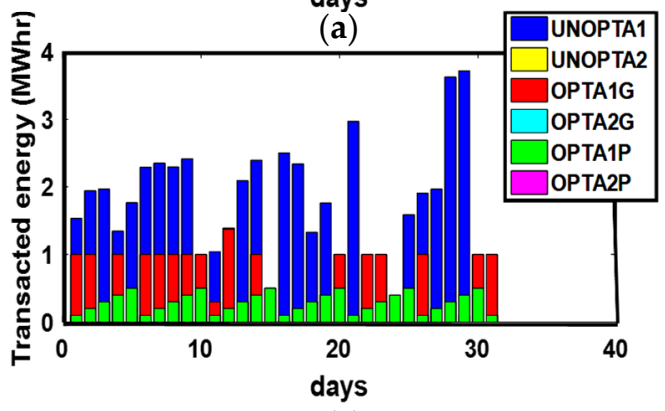

(c)

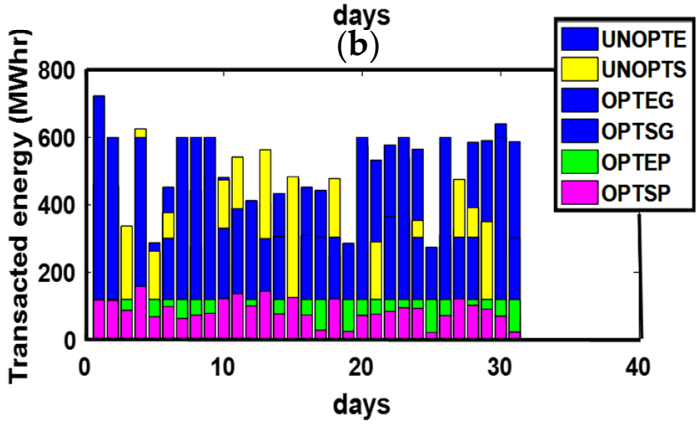

(d)

Figure 5. (a) P-C, (b) P-P, (c) ED-ED, and (d) ED-SG Energy Transactions. (a) UNOPTA1: Unoptimized Consumer Energy, OPTA2 (GA): GA Optimized consumer energy, OPTA3 (PSO): PSO consumer energy; (b) UNOPTA1: Prosumer 1 Unoptimized transacted energy, UNOPTA2: Prosumer 2 Unoptimized transacted energy, OPTA1G: Prosumer 1 GA Optimized transacted energy, OPTA2G: Prosumer 2 GA Optimized transacted energy, OPTA1P: Prosumer 1 PSO transacted energy, OPTA2P: Prosumer 2 PSO transacted energy; (c) UNOPTA1: ED1 Unoptimized transacted energy, UNOPTA2: ED2 Unoptimized transacted energy, OPTA1G: ED1 GA Optimized transacted energy, OPTA2G: ED2 GA Optimized transacted energy, OPTA1P: ED1 PSO transacted energy, OPTA2P: ED2 PSO transacted energy; (d) ED-SG Energy Transaction, UNOPTE: ED Unoptimized transacted energy, UNOPTS: SG Unoptimized transacted energy, OPTEG: ED GA Optimized transacted energy, OPTSG: SG GA Optimized transacted energy, OPTEP: ED PSO transacted energy, OPTSP: SG PSO transacted energy. 
Due to the availability of energy surplus, enough energy transactions are performed between P-C, P-P, and ED-ED throughout the month. Increased PES permits prosumer to export energy to the grid as illustrated in Figure 5.

\subsubsection{Autumn Season}

The Autumn season is observed in Queensland, Australia in March, April, and May, where 4.39 peak sun h/day is recorded as the average sun performance during the Autumn season with an average wind speed of $3.5 \mathrm{~m} / \mathrm{s}$. The maximum surplus energy generation on the 3rd and 16th of March results in minimized PEC as depicted from Figure 6. The increased PES on the 3rd, 11th, 16th, 20th, and 29th of March permits ED to export energy to the grid, contributing to escalated GR. Figure 7 presents energy transactions performed between P-C, P-P, ED-ED, and ED-SG, respectively.

\subsubsection{Winter Season}

The Winter season is observed in Queensland, Australia from June to August. June has the worst average solar performance with 5.36 peak sun $\mathrm{h} /$ day. The average wind speed in Queensland from June to August is $3.8 \mathrm{~m} / \mathrm{s}$. The optimized and unoptimized PEC, PES, and GR are presented in Figure 8 . The 4th, 10th, 15th, 24th, and 31st of July have the maximum while the 6th, 13th, 14th, 20th, 26th, and 27th of July have the minimum PEC. The maximum PES is observed on the 6th, 13th, 14th, 20th, 26th, and 27th of July. The 4th, 10th, 15th, 24th, and 31st of July exhibits low PES leading prosumer towards grid energy import and a reduced PEC. Days with low PES (4th, 10th, 15th, 24th, and 31st of July) result in decreased GR while the maximum GR is observed on the days of high PES. Figure 9 demonstrates the number of unoptimized and optimized energy transactions performed between P-C, P-P, ED-ED, and ED-SG throughout the month. Due to the minimum wind speed and solar radiance, minimal energy transactions are accomplished throughout the month. GA maximizes the number of energy transactions more so than PSO as depicted in Figure 9 .

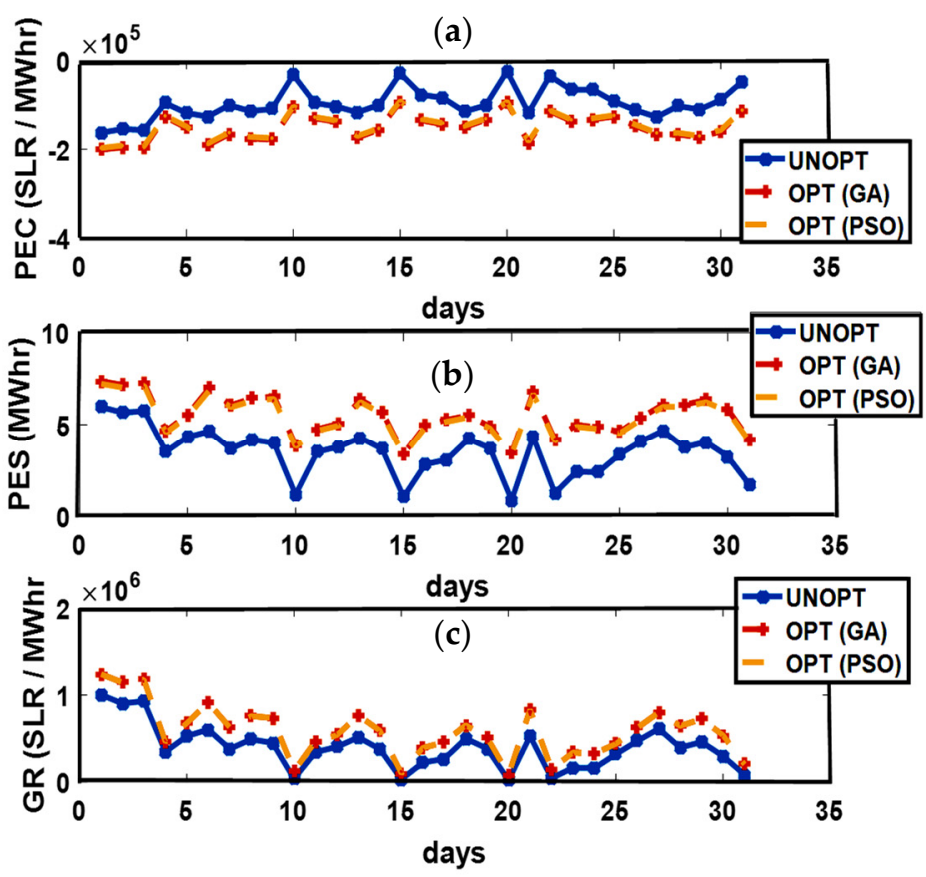

Figure 6. (a) Prosumer Energy Cost (PEC), (b) Prosumer Energy Surplus (PES), (c) Grid Revenue (GR). 

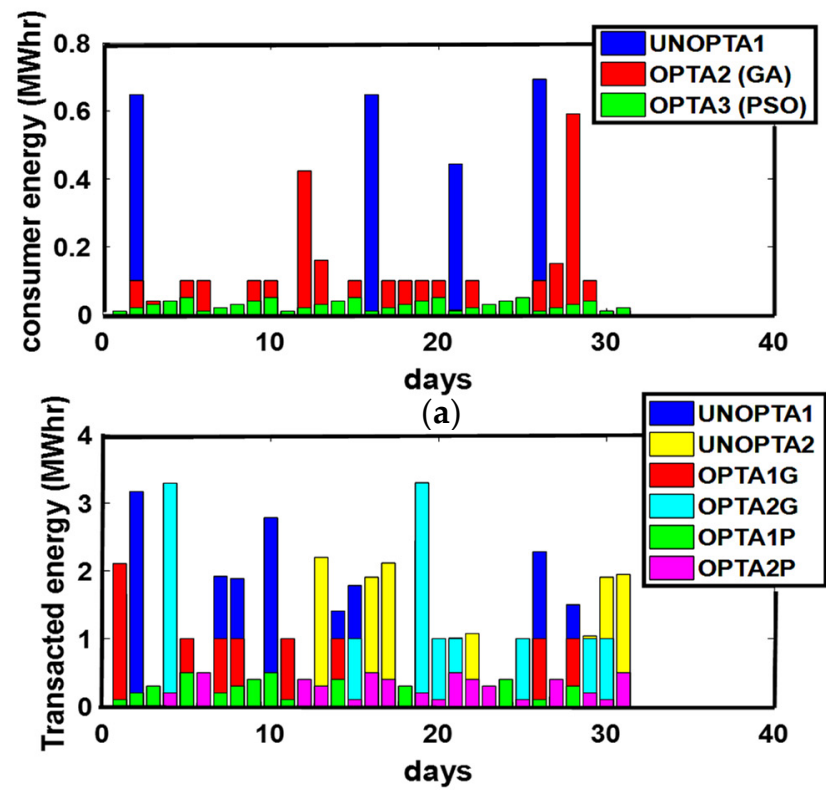

(c)
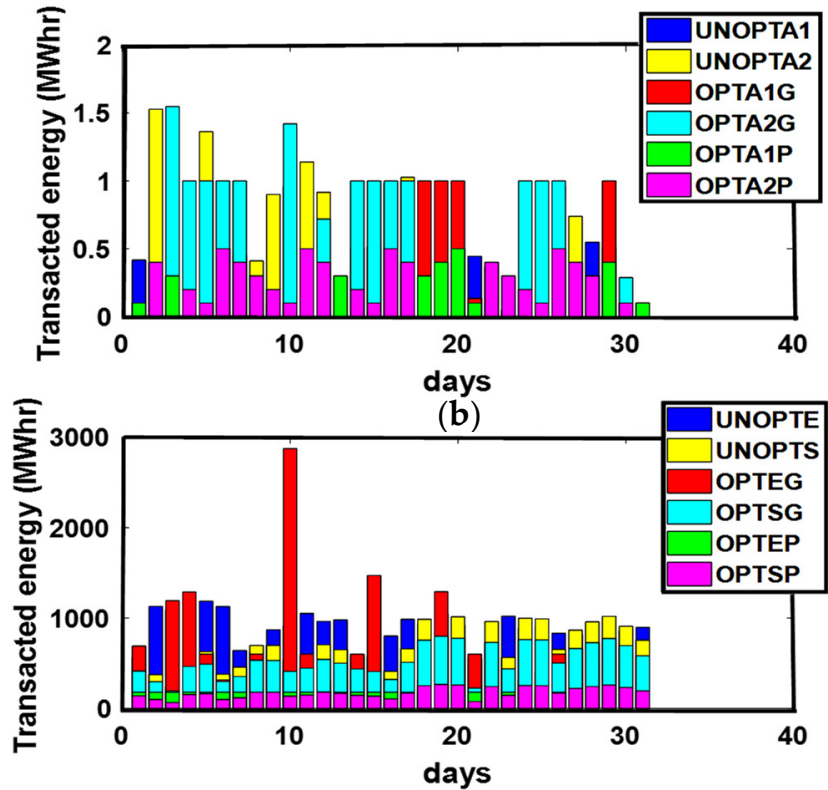

(d)

Figure 7. (a) P-C, (b) P-P, (c) ED-ED, and (d) ED-SG Energy Transactions. (a) UNOPTA1: Unoptimized Consumer Energy, OPTA2 (GA): GA Optimized consumer energy, OPTA3 (PSO): PSO consumer energy; (b) UNOPTA1: Prosumer 1 Unoptimized transacted energy, UNOPTA2: Prosumer 2 Unoptimized transacted energy, OPTA1G: Prosumer 1 GA Optimized transacted energy, OPTA2G: Prosumer 2 GA Optimized transacted energy, OPTA1P: Prosumer 1 PSO transacted energy, OPTA2P: Prosumer2 PSO transacted energy; (c) UNOPTA1: ED1 Unoptimized transacted energy, UNOPTA2: ED2 Unoptimized transacted energy, OPTA1G: ED1 GA Optimized transacted energy, OPTA2G: ED2 GA Optimized transacted energy, OPTA1P: ED1 PSO transacted energy, OPTA2P: ED2 PSO transacted energy; (d) UNOPTE: ED Unoptimized transacted energy, UNOPTS: SG Unoptimized transacted energy, OPTEG: ED GA Optimized transacted energy, OPTSG: SG GA Optimized transacted energy, OPTEP: ED PSO transacted energy, OPTSP: SG PSO transacted energy.

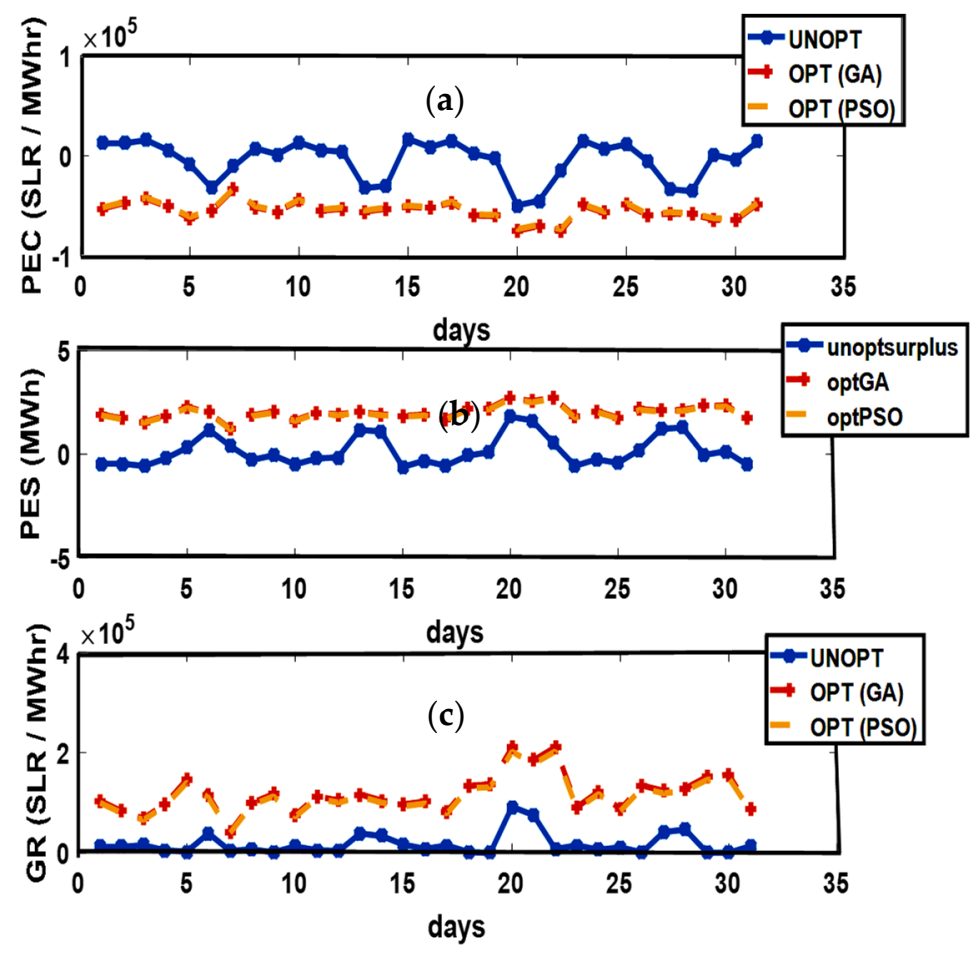

Figure 8. (a) Prosumer Energy Cost (PEC), (b) Prosumer Energy Surplus (PES), (c) Grid Revenue (GR). 

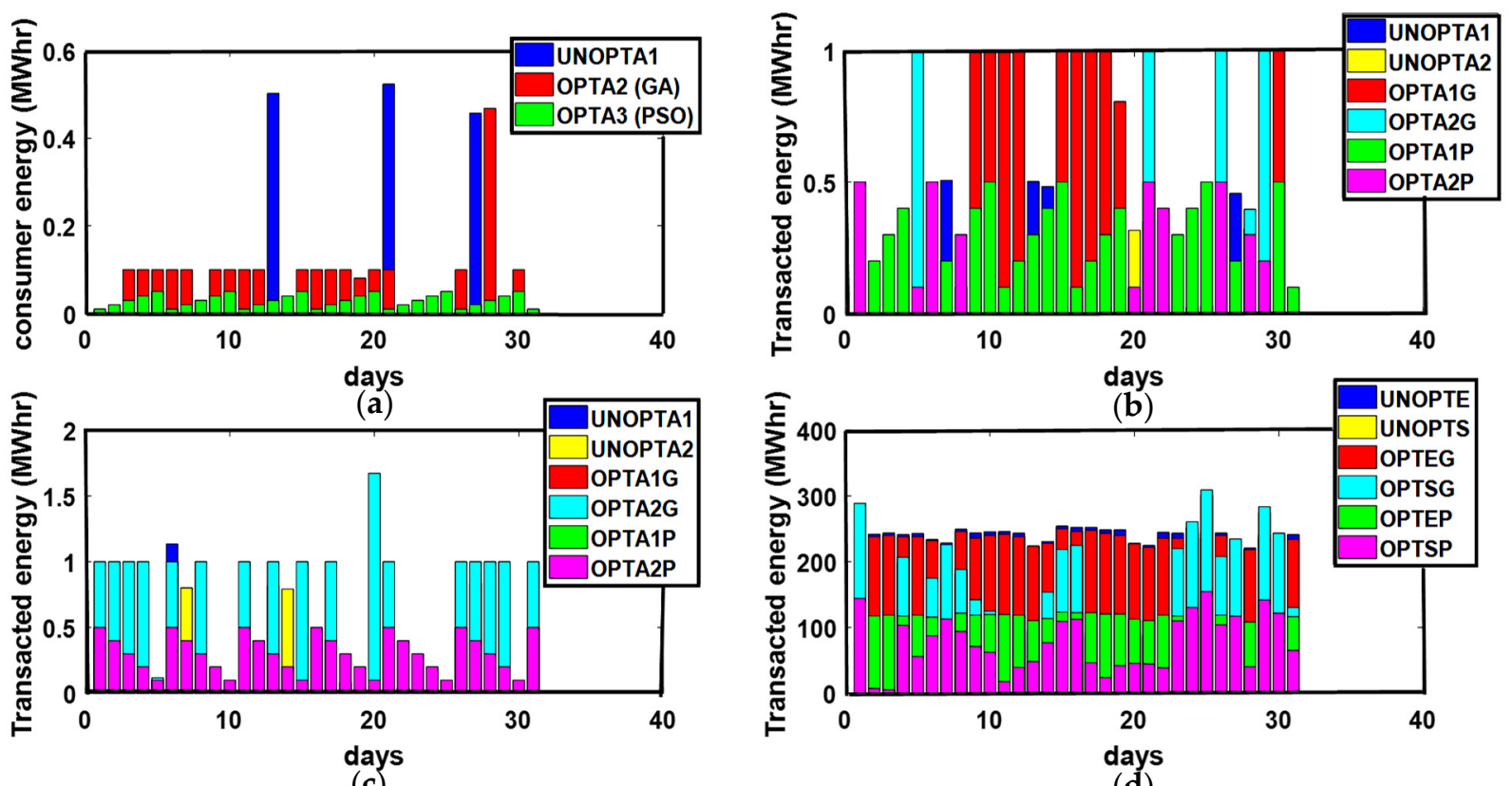

(c)

(d)

Figure 9. (a) P-C, (b) P-P, (c) ED-ED, and (d) ED-SG Energy Transactions. (a) UNOPTA1: Unoptimized Consumer Energy, OPTA2 (GA): GA Optimized consumer energy, OPTA3 (PSO): PSO consumer energy; (b) UNOPTA1: Prosumer 1 Unoptimized transacted energy, UNOPTA2: Prosumer 2 Unoptimized transacted energy, OPTA1G: Prosumer 1 GA Optimized transacted energy, OPTA2G: Prosumer 2 GA Optimized transacted energy, OPTA1P: Prosumer 1 PSO transacted energy, OPTA2P: Prosumer 2 PSO transacted energy; (c) ED-ED Energy Transaction, UNOPTA1: ED1 Unoptimized transacted energy, UNOPTA2: ED2 Unoptimized transacted energy, OPTA1G: ED1 GA Optimized transacted energy, OPTA2G: ED2 GA Optimized transacted energy, OPTA1P: ED1 PSO transacted energy, OPTA2P: ED2 PSO transacted energy; (d) ED-SG Energy Transaction, UNOPTE: ED Unoptimized transacted energy, UNOPTS: SG Unoptimized transacted energy, OPTEG: ED GA Optimized transacted energy, OPTSG: SG GA Optimized transacted energy, OPTEP: ED PSO transacted energy, OPTSP: SG PSO transacted energy.

4.2.5. Comparative Analysis of Genetic Algorithm (GA) Optimization and Particle Swarm Optimization (PSO)

Optimization of PEC, PES, and GR performed through the GA and PSO algorithms is comparatively analyzed in this work. Optimized results achieved through GA outperform the PSO results. The maximum reduction of PEC is accomplished using GA in all four seasons compared to PSO. Similarly, GA assists in the maximization of PES and GR more effectively than PSO.

Table 4 summarizes the average results of GA optimization and PSO for three EDs. The table shows average change observed between unoptimized and optimized results of GA is more than the average change of PSO results and signifies the better performance of GA in this work.

\subsubsection{SolarCoin (SLR) Blockchain Implementation}

Figure 10 demonstrates energy transactions performed between a prosumer and a consumer on the SLR blockchain. The record of the transaction exhibits an encrypted hash of the block, the address of prosumer and consumer, the time of the transaction, and the amount of energy /SLR transacted. A consumer with the address "s0987654321dfghjkl" requests $0.043014 \mathrm{MW}$ of energy on the network. The system searches for a prosumer on the network owning 0.043014 MW surplus energy. The system connects the consumer with the prosumer with the address "x123456789zcvbnm". SC executes and implements the encoded constraints. On successful implementation of constraints, the prosumer sells the required energy to the consumer and the consumer pays the prosumer with 1172 SLRs. 
Table 4. Comparative analysis of GA and PSO optimized results.

\begin{tabular}{|c|c|c|c|c|c|c|c|}
\hline \multirow[b]{2}{*}{ EDs } & \multirow[b]{2}{*}{$\begin{array}{l}\text { Month, } \\
\text { Year }\end{array}$} & \multicolumn{3}{|c|}{ GA optimization Results } & \multicolumn{3}{|c|}{ PSO Results } \\
\hline & & $\begin{array}{c}\Delta \text { PEC } \\
\left(\times 10^{5}\right)\end{array}$ & $\triangle \mathrm{PES}$ & $\begin{array}{c}\Delta \mathrm{GR} \\
\left(\times 10^{5}\right)\end{array}$ & $\begin{array}{c}\Delta \text { PEC } \\
\left(\times 10^{5}\right)\end{array}$ & $\triangle \mathrm{PES}$ & $\begin{array}{c}\Delta \mathrm{GR} \\
\left(\times 10^{5}\right)\end{array}$ \\
\hline \multirow{10}{*}{ ED1 } & July, 19 & 2.76 & 1.9217 & 0.918 & 2.75 & 1.8840 & 0.877 \\
\hline & Aug, 19 & 0.24 & 0.8815 & 0.9407 & 0.228 & 0.836 & 0.8773 \\
\hline & Sep, 19 & 0.86 & 2.838 & 4.3440 & 0.242 & 2.757 & 4.157 \\
\hline & Oct, 19 & 0.53 & 1.9505 & 4.9613 & 0.501 & 1.836 & 4.9613 \\
\hline & Nov, 19 & 0.531 & 1.949 & 2.9284 & 0.512 & 1.878 & 2.783 \\
\hline & Dec, 19 & 0.302 & 1.109 & 2.3639 & 0.279 & 1.025 & 2.158 \\
\hline & Jan, 20 & 0.39 & 1.407 & 2.369 & 0.3446 & 1.263 & 2.369 \\
\hline & Feb, 20 & 0.295 & 1.042 & 2.2345 & 0.284 & 1.042 & 2.051 \\
\hline & Mar, 20 & 0.325 & 1.237 & 1.1018 & 0.314 & 1.151 & 1.025 \\
\hline & April, 20 & 0.529 & 1.976 & 3.1470 & 0.5188 & 1.902 & 2.987 \\
\hline \multirow{10}{*}{ ED2 } & July, 19 & 0.487 & 1.786 & 2.6009 & 0.46881 & 1.718 & 2.468 \\
\hline & Aug, 19 & 0.605 & 2.218 & 3.4539 & 0.5845 & 2.142 & 3.389 \\
\hline & Sep, 19 & 0.7293 & 2.674 & 5.7227 & 0.70208 & 2.573 & 5.4344 \\
\hline & Oct, 19 & 0.6060 & 2.2218 & 3.9258 & 0.5834 & 2.138 & 3.7288 \\
\hline & Nov, 19 & 0.5389 & 2.2251 & 1.3293 & 0.5883 & 2.1815 & 1.336 \\
\hline & Dec, 19 & 0.58864 & 2.0396 & 1.1556 & 0.5271 & 1.9996 & 1.1097 \\
\hline & Jan, 20 & 0.4294 & 1.574 & 1.1538 & 0.4182 & 1.5331 & 1.106 \\
\hline & Feb, 20 & 0.4118 & 1.5095 & 1.7659 & 0.3983 & 1.46 & 1.435 \\
\hline & Mar, 20 & 0.8454 & 3.0994 & 5.0045 & 0.822 & 3.0129 & 4.791 \\
\hline & April, 20 & 0.64577 & 2.3672 & 2.0054 & 0.6311 & 2.313 & 5.235 \\
\hline \multirow{10}{*}{ ED3 } & July, 19 & 29.535 & 108.2 & 6839.2 & 28.64 & 105 & 6537 \\
\hline & Aug, 19 & 35.674 & 130.7 & 9327.9 & 34.649 & 127 & 8924 \\
\hline & Sep, 19 & 33.122 & 121.4 & 11,238 & 31.92 & 117 & 10,685 \\
\hline & Oct, 19 & 34.794 & 127.5 & 12,047 & 33.55 & 123 & 11,461 \\
\hline & Nov, 19 & 41.191 & 150.9 & 15,201 & 39.832 & 146 & 14,495 \\
\hline & Dec, 19 & 40.268 & 147.6 & 13,396 & 39.013 & 143 & 12,792 \\
\hline & Jan, 20 & 46.878 & 171.82 & 15,548 & 45.561 & 167 & 14,883 \\
\hline & Feb, 20 & 34.109 & 125.02 & 10,063 & 33.012 & 121 & 9602 \\
\hline & Mar, 20 & 40.216 & 147.4 & 21,058 & 38.468 & 141 & 19,888 \\
\hline & April, 20 & 35.062 & 128.51 & 29,995 & 33.284 & 122 & 18,234 \\
\hline
\end{tabular}

Abbreviations: $\triangle$ PEC: Average change between optimized and unoptimized PEC; $\triangle$ PES: Average change between optimized and unoptimized PES; $\triangle$ GR: Average change between optimized and unoptimized GR.

B lock 1

\begin{tabular}{|c|}
\hline dfgty345676542234 \\
\hline 1234678ihgnvefgrss \\
\hline from: x123456789zevbnm \\
to: s $0987654321 \mathrm{~d}$ fghjkl \\
Energy transacted: $0.043014 \mathrm{MWhr}$ \\
Amount transacted: 1173 Solar Coins \\
Timestamp =01-Apr-2020 17:37:22 \\
\hline
\end{tabular}

Block 2

\begin{tabular}{|c|}
\hline mnjkouyt 677894323 \\
\hline dfgty345676542234 \\
\hline from: $x 123456789$ zevbnm \\
to: $\mathrm{s} 0987654321 \mathrm{~d}$ fghjkl \\
Energy transacted: $0.039179 \mathrm{MWhr}$ \\
Amount transacted: 867 Solar Coins \\
Timestamp $=02-$ Apr-2020 15:47:20
\end{tabular}

Block n

\begin{tabular}{|c|c|}
\cline { 2 - 3 } & cvbnhjyi6676432asd \\
\cline { 2 - 3 } & 56790lokhgfdsssdfrt \\
\cline { 2 - 3 } & $\begin{array}{c}\text { from: } x 123456789 \text { zevbnm } \\
\text { to: s0987654321dfghjkl } \\
\text { Energy transacted: } 0.066446 \mathrm{MWhr} \\
\text { Amount transacted: } 1812 \text { Solar Coins } \\
\text { Timestamp = 06-Apr-2020 21:57:42 }\end{array}$ \\
\hline
\end{tabular}

Figure 10. Blockchain transaction.

\subsection{Prosumer Energy Cost (PEC) and Prosumer Energy Surplus (PES)}

Figure 11 signifies the impact of the variation of PES on PEC. An increase in the PES on account of the increased peak sun $\mathrm{h} /$ day and increased wind speed eliminates the need for energy import from the grid, resulting in a decreased PEC as depicted in Figure 11. For each MWhr rise in PES, PEC subsequently decreases. 


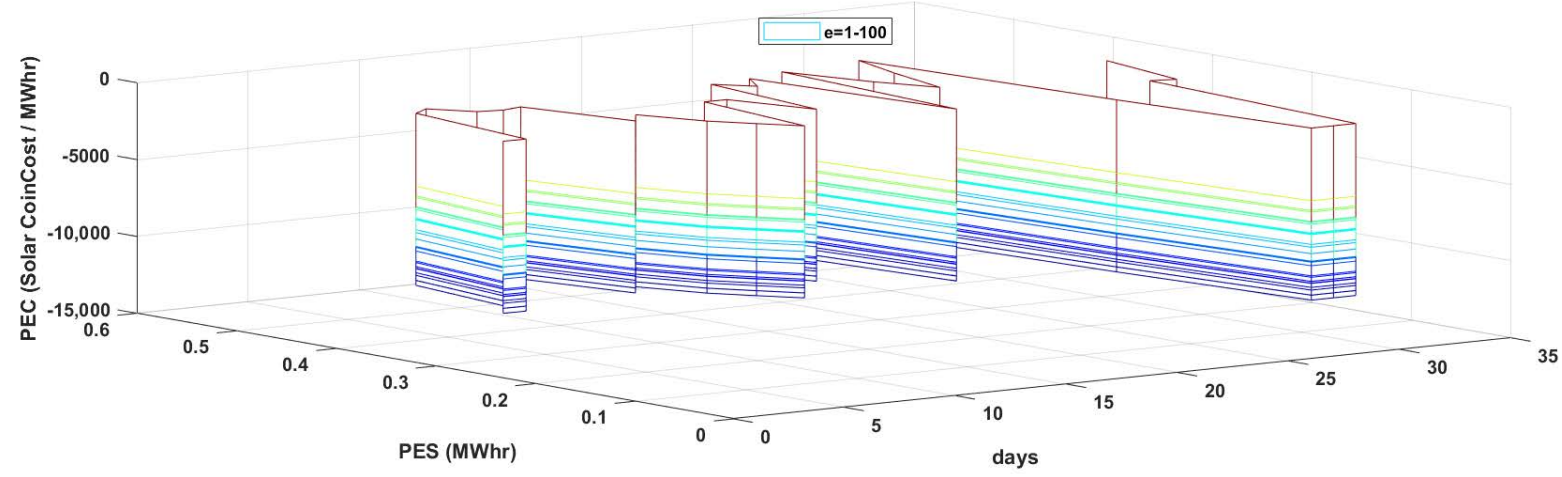

Figure 11. PES and PEC comparison.

\subsection{Critical Analysis}

The comparative tabular analysis of unoptimized and optimized GA DSM is scrutinized in this sub-section. Aggregate energy transactions accomplished in all four seasons are extensively analyzed.

\subsubsection{Comparative Analysis of Demand Management}

Table 5 presents the comparative statistics of DSM performed on the proposed SLR blockchain-based METM. Unoptimized and GA-optimized results for ED1, ED2, and ED3 enveloping PEC, PES, and GR are manifested in this table. The average change observed between unoptimized and optimized results of the three EDs is analyzed. The table shows GA optimized results surpass the unoptimized results. PEC is effectively minimized throughout the year as a result of optimization of EDs' demand. Similarly, energy surplus is maximized empowering prosumers to satisfy their load requirements and import energy to SG, resulting in an increased GR for prosumers.

Table 5. Comparative analysis of unoptimized and GA optimized results.

\begin{tabular}{|c|c|c|c|c|c|c|c|c|c|c|}
\hline EDs & $\begin{array}{l}\text { Month, } \\
\text { Year }\end{array}$ & $\begin{array}{c}\text { PEC } \\
\text { (un-opt) } \\
\left(\times 10^{5}\right)\end{array}$ & $\begin{array}{c}\text { PEC } \\
(\text { opt })\left(\times 10^{5}\right)\end{array}$ & $\begin{array}{c}\Delta P E C \\
\left(\times 10^{5}\right)\end{array}$ & $\begin{array}{c}\text { PES } \\
\text { (un-opt) }\end{array}$ & $\begin{array}{l}\text { PES } \\
\text { (opt) }\end{array}$ & $\triangle \mathrm{PES}$ & $\begin{array}{c}\text { GR } \\
(\text { un-opt }) \\
\left(\times 10^{5}\right)\end{array}$ & $\begin{array}{l}\text { GR (opt) } \\
\left(\times 10^{5}\right)\end{array}$ & $\begin{array}{c}\Delta \mathrm{GR} \\
\left(\times 10^{5}\right)\end{array}$ \\
\hline \multirow{10}{*}{ ED1 } & July, 19 & 1.94 & -4.70 & 2.76 & 0 & 1.9217 & 1.9217 & 0.12386 & 1.0412 & 0.9182 \\
\hline & Aug, 19 & -0.393 & -0.633 & 0.24 & 1.4412 & 2.3227 & 0.8815 & 0.58619 & 1.5226 & 0.9407 \\
\hline & Sep, 19 & -0.35 & -1.21 & 0.86 & 1.2924 & 4.1307 & 2.838 & 0.47139 & 4.8154 & 4.3440 \\
\hline & Oct, 19 & -1.05 & -1.58 & 0.53 & 3.8686 & 5.8191 & 1.9505 & 4.2237 & 9.185 & 4.9613 \\
\hline & Nov, 19 & -0.46 & -0.991 & 0.531 & 1.6862 & 3.6359 & 1.949 & 0.80243 & 3.7309 & 2.9284 \\
\hline & Dec, 19 & -0.878 & -1.18 & 0.302 & 3.2188 & 4.3286 & 1.109 & 2.9240 & 5.2879 & 2.3639 \\
\hline & Jan, 20 & -1.62 & -2.01 & 0.39 & 5.9638 & 7.3715 & 1.407 & 10.038 & 12.407 & 2.369 \\
\hline & Feb, 20 & -0.80913 & -1.104 & 0.295 & 2.9658 & 4.0082 & 1.042 & 2.4824 & 4.7169 & 2.2345 \\
\hline & Mar, 20 & -0.8605 & -1.186 & 0.325 & 3.1544 & 4.3921 & 1.237 & 2.8082 & 3.9100 & 1.1018 \\
\hline & April, 20 & -0.499 & -1.0289 & 0.529 & 1.8320 & 3.8088 & 1.976 & 0.94719 & 4.0942 & 3.1470 \\
\hline \multirow{10}{*}{ ED2 } & July, 19 & -0.46 & -0.947 & 0.487 & 1.6861 & 3.4726 & 1.786 & 0.80233 & 3.4033 & 2.6009 \\
\hline & Aug, 19 & -0.4499 & -1.055 & 0.605 & 1.6492 & 3.8676 & 2.218 & 0.76760 & 4.2215 & 3.4539 \\
\hline & Sep, 19 & -0.66962 & -1.399 & 0.7293 & 2.4544 & 5.1285 & 2.674 & 1.7001 & 7.4228 & 5.7227 \\
\hline & Oct, 19 & -0.55098 & -1.157 & 0.6060 & 2.0195 & 4.2413 & 2.2218 & 1.1510 & 5.0768 & 3.9258 \\
\hline & Nov, 19 & 0.06806 & -0.6070 & 0.5389 & 0 & 2.2251 & 2.2251 & 0.068 & 1.3973 & 1.3293 \\
\hline & Dec, 19 & 0.01836 & -0.556 & 0.58864 & 0 & 2.0396 & 2.0396 & 0.01836 & 1.1740 & 1.1556 \\
\hline & Jan, 20 & -0.1396 & -0.569 & 0.4294 & 0.5117 & 2.0857 & 1.574 & 0.07389 & 1.2277 & 1.1538 \\
\hline & Feb, 20 & -0.2762 & -0.688 & 0.4118 & 1.0124 & 2.5219 & 1.5095 & 0.02892 & 1.7949 & 1.7659 \\
\hline & Mar, 20 & -0.3576 & -1.203 & 0.8454 & 1.3110 & 4.4104 & 3.0994 & 0.48506 & 5.4896 & 5.0045 \\
\hline & April, 20 & -0.10343 & -0.7492 & 0.64577 & 0.3791 & 2.7463 & 2.3672 & 0.04056 & 2.0460 & 2.0054 \\
\hline
\end{tabular}


Table 5. Cont.

\begin{tabular}{|c|c|c|c|c|c|c|c|c|c|c|}
\hline EDs & $\begin{array}{l}\text { Month, } \\
\text { Year }\end{array}$ & $\begin{array}{c}\text { PEC } \\
\text { (un-opt) } \\
\left(\times 10^{5}\right)\end{array}$ & $\begin{array}{c}\text { PEC } \\
(o p t)\left(\times 10^{5}\right)\end{array}$ & $\begin{array}{c}\triangle P E C \\
\left(\times 10^{5}\right)\end{array}$ & $\begin{array}{c}\text { PES } \\
\text { (un-opt) }\end{array}$ & $\begin{array}{l}\text { PES } \\
\text { (opt) }\end{array}$ & $\triangle \mathrm{PES}$ & $\begin{array}{c}\text { GR } \\
(\text { un-opt }) \\
\left(\times 10^{5}\right)\end{array}$ & $\begin{array}{c}\text { GR (opt) } \\
\left(\times 10^{5}\right)\end{array}$ & $\begin{array}{c}\Delta \mathrm{GR} \\
\left(\times 10^{5}\right)\end{array}$ \\
\hline \multirow{10}{*}{ ED3 } & July, 19 & -15.769 & -45.304 & 29.535 & 57.8000 & 166.05 & 108.2 & 942.85 & 7782.1 & 6839.2 \\
\hline & Aug, 19 & -16.642 & -52.316 & 35.674 & 61 & 191.76 & 130.7 & 1050.1 & 10,378 & 9327.9 \\
\hline & Sep, 19 & -28.183 & -61.305 & 33.122 & 103.300 & 224.70 & 121.4 & 3011.5 & 14,250 & 11,238 \\
\hline & Oct, 19 & -28.264 & -63.058 & 34.794 & 103.600 & 231.13 & 127.5 & 3029.1 & 15,077 & 12,047 \\
\hline & Nov, 19 & -28.073 & -69.264 & 41.191 & 102.900 & 253.87 & 150.9 & 2988.3 & 18,190 & 15,201 \\
\hline & Dec, 19 & -23.736 & -64.004 & 40.268 & 87 & 234.60 & 147.6 & 2136.1 & 15,533 & 13,396 \\
\hline & Jan, 20 & -20.298 & -67.176 & 46.878 & 74.4000 & 246.22 & 171.82 & 1562.2 & 17,111 & 15,548 \\
\hline & Feb, 20 & -21.853 & -55.962 & 34.109 & 80.1000 & 205.12 & 125.02 & 1810.7 & 11,874 & 10,063 \\
\hline & Mar, 20 & -48.944 & -89.160 & 40.216 & 179.400 & 326.80 & 147.4 & 9083.1 & 30,142 & 21,058 \\
\hline & April, 20 & -55.601 & -90.663 & 35.062 & 203.800 & 332.31 & 128.51 & 11,722 & 31,167 & 29,995 \\
\hline
\end{tabular}

\subsubsection{Smart Contract Validation}

Extensive variation in solar radiation and wind speed throughout the year influence the aggregated RE generation engendering enough or reduced energy transactions. The averaged percentage of unoptimized, GA-optimized, and PSO-based energy transactions accomplished in each month are summarized in Table 6. The table shows that the percentage of optimized transactions is more than the percentage of unoptimized energy transactions. In addition, the percentage change of GA optimized energy transactions is greater than the average change observed in PSO.

Table 6. Percentage energy transactions.

\begin{tabular}{|c|c|c|c|c|c|c|}
\hline Nodes & $\begin{array}{l}\text { Month, } \\
\text { Year }\end{array}$ & $\begin{array}{c}\% \text { ET } \\
\text { (un-opt) }\end{array}$ & $\begin{array}{c}\% \text { ET } \\
\text { (opt-GA) }\end{array}$ & $\begin{array}{c}\Delta \% \text { ET } \\
\text { (GA) }\end{array}$ & $\begin{array}{c}\% \text { ET } \\
\text { (opt-PSO) }\end{array}$ & $\begin{array}{r}\Delta \% \text { ET } \\
\text { (PSO) }\end{array}$ \\
\hline \multirow{10}{*}{ P-C } & July, 19 & 10 & 100 & 90 & 100 & 90 \\
\hline & Aug, 19 & 35 & 100 & 65 & 100 & 65 \\
\hline & Sep, 19 & 7 & 97 & 90 & 96 & 89 \\
\hline & Oct, 19 & 39 & 94 & 55 & 93 & 54 \\
\hline & Nov, 19 & 40 & 100 & 60 & 100 & 60 \\
\hline & Dec, 19 & 42 & 100 & 58 & 99 & 57 \\
\hline & Jan, 20 & 35 & 97 & 62 & 97 & 62 \\
\hline & Feb, 20 & 14 & 100 & 86 & 98 & 84 \\
\hline & Mar, 20 & 13 & 100 & 87 & 97 & 84 \\
\hline & April, 20 & 19 & 100 & 81 & 99 & 80 \\
\hline \multirow{10}{*}{ P-P } & July, 19 & 11 & 43 & 32 & 42 & 31 \\
\hline & Aug, 19 & 32 & 50 & 18 & 50 & 18 \\
\hline & Sep, 19 & 29 & 48 & 19 & 48 & 19 \\
\hline & Oct, 19 & 45 & 48 & 3 & 48 & 3 \\
\hline & Nov, 19 & 47 & 48 & 1 & 46 & 1 \\
\hline & Dec, 19 & 47 & 48 & 1 & 47 & 0 \\
\hline & Jan, 20 & 45 & 48 & 3 & 48 & 3 \\
\hline & Feb, 20 & 72 & 90 & 18 & 89 & 17 \\
\hline & Mar, 20 & 31 & 43 & 12 & 41 & 10 \\
\hline & April, 20 & 30 & 42 & 12 & 40 & 10 \\
\hline \multirow{10}{*}{ ED-ED } & July, 19 & 10 & 48 & 38 & 46 & 36 \\
\hline & Aug, 2019 & 20 & 48 & 28 & 47 & 27 \\
\hline & Sep, 19 & 35 & 50 & 15 & 49 & 14 \\
\hline & Oct, 19 & 48 & 50 & 2 & 50 & 2 \\
\hline & Nov, 19 & 48 & 52 & 4 & 51 & 3 \\
\hline & Dec, 19 & 52 & 70 & 18 & 69 & 17 \\
\hline & Jan, 20 & 37 & 50 & 13 & 48 & 11 \\
\hline & Feb, 20 & 50 & 46 & 4 & 46 & 4 \\
\hline & Mar, 20 & 42 & 48 & 6 & 46 & 4 \\
\hline & April, 20 & 39 & 40 & 1 & 40 & 1 \\
\hline
\end{tabular}




\section{Conclusions and Future Work}

A central authority supervising energy and financial transactions in an energy sector experiences a substantial computational burden. Stakeholders are being charged for each transaction made by a central authority and the privacy of their transactions' profile is greatly at threat. The trading approach in a decentralized fashion bypassing central authority is greatly in need. Blockchain technology underpins peer-to-peer energy transactions and eliminates the issues associated with the central authority. SLR blockchain-based METM is proposed to permit a decentralized energy trading concept. Two Solar EDs and a Wind ED incorporating N-SEPs, N-WEPs, and N-consumers are deployed in the proposed model. Energy transactions are carried out between P-C, P-P, ED-ED, and ED-SG. SLRs are exchanged among the users as a result of energy trading. The demand-side optimization problem is formulated using GA and PSO for the maximization of PES and GR and minimization of PEC. The performance of the SLR blockchain-based METM is evaluated in all four seasons. The unoptimized, GA-optimized, and PSO results of four seasons are critically and comparatively analyzed. Maximum energy surplus is generated in the Summer and Spring (52 percent) seasons on account of the high wind speed and enough solar radiations. Seventy-one percent of GR is earned in the Summer and Spring seasons. Similarly, the minimum PEC is observed in the Spring and Summer (53 percent) seasons compared to the Autumn and Winter seasons. The GA optimized results outperform the PSO results. GA maximizes PES on average by 29 percent compared to PSO (28 percent). The uncertainty confronted by the RE generation affects the average energy transactions carried out in each season. Thirty-nine percent of energy transactions are accomplished between $\mathrm{P}-\mathrm{C}$ in the Spring season and 35 percent in the Summer season compared to Autumn (13 percent) and Winter (10 percent) season. Similarly, GA effectively maximizes the percentage of energy transactions accomplished as compared to PSO. A 62 percent average increase in energy transactions carried out between P-C by GA optimization is observed in the Summer season compared to that carried out by PSO (60 percent).

The scalability of our proposed model incorporating multiple energy transactions among numerous EDs and SG at one time is a possible future direction of this work. Furthermore, issues coupled with the scalability of blockchain technology need to be addressed in the future. Speed and security are the major directions of improvement in a scaled blockchain network.

Author Contributions: Conceptualization, S.R., B.K., and S.M.A.; methodology, J.A.; software, S.R.; validation, B.K.; formal analysis, B.K.; investigation, S.M.A.; resources, B.K.; data curation, S.M.A.; writing-original draft preparation, S.R.; writing—review and editing, Z.U.; visualization, J.A.; supervision, B.K.; project administration, Z.U.; funding acquisition, A.J.A. and A.A. All authors have read and agreed to the published version of the manuscript.

Funding: This work was supported by the Deanship of Scientific Research at Umm Al-Qura University under Grant 19-COM-1-01-0017.

Institutional Review Board Statement: Not Applicable.

Informed Consent Statement: Not Applicable.

Data Availability Statement: This study did any report any data.

Acknowledgments: We are thankful to COMSATS University Islamabad, Abbottabad Campus for providing a simulation Laboratory to validate our results.

Conflicts of Interest: The authors declare no conflict of interest. 


\section{Nomenclature}

$\begin{array}{ll}\text { Acronyms } & \text { Definitions } \\ \text { C } & \text { Consumer } \\ \text { DRP } & \text { Demand Response Program } \\ \text { DSM } & \text { Demand-Side Management } \\ \text { EDs } & \text { Energy Districts } \\ \text { EM } & \text { Energy Management } \\ \text { GA } & \text { Genetic Algorithm } \\ \text { GR } & \text { Grid Revenue } \\ \text { MEC } & \text { Mutual Energy Contract } \\ \text { METM } & \text { Mutual Energy Trade Model } \\ \text { P } & \text { Prosumer } \\ \text { PEC } & \text { Prosumer Energy Cost } \\ \text { PES } & \text { Prosumer Energy Surplus } \\ \text { PSO } & \text { Particle Swarm Optimization } \\ \text { P2P } & \text { Peer-to-peer } \\ \text { RE } & \text { Renewable Energy } \\ \text { SC } & \text { Smart Contract } \\ \text { SEPs } & \text { Solar Energy Prosumers } \\ \text { SG } & \text { Smart Grid } \\ \text { SLRs } & \text { Solar Coins } \\ \text { WEPs } & \text { Wind Energy Prosumers }\end{array}$

\section{References}

1. Pieroni, A.; Scarpato, N.; Nunzio, L.D.; Fallucchi, F.; Raso, M. Smarter City: Smart Energy Grid based on Blockchain Technology. Int. J. Adv. Sci. Eng. Inf. Technol. 2018, 8, 298. [CrossRef]

2. Mengelkamp, E.; Gärttner, J.; Rock, K.; Kessler, S.; Orsini, L.; Weinhardt, C. Designing microgrid energy markets. Appl. Energy 2018, 210, 870-880. [CrossRef]

3. Laszka, A.; Eisele, S.; Dubey, A.; Karsai, G.; Kvaternik, K. TRANSAX: A Blockchain-Based Decentralized Forward-Trading Energy Exchanged for Transactive Microgrids. In 2018 IEEE 24th International Conference on Parallel and Distributed Systems (ICPADS); Institute of Electrical and Electronics Engineers (IEEE): Singapore, 2018; pp. 918-927.

4. Hasankhani, A.; Hakimi, S.M.; Shafie-Khah, M.; Asadolahi, H. Blockchain technology in the future smart grids: A comprehensive review and frameworks. Int. J. Electr. Power Energy Syst. 2021, 129, 106811. [CrossRef]

5. Shaukat, N.; Khan, B.; Ali, S.; Mehmood, C.; Khan, J.; Farid, U.; Majid, M.; Anwar, S.; Jawad, M.; Ullah, Z. A survey on electric vehicle transportation within smart grid system. Renew. Sustain. Energy Rev. 2018, 81, 1329-1349. [CrossRef]

6. Asghar, R.; Rehman, F.; Ullah, Z.; Qamar, A.; Ullah, K.; Iqbal, K.; Aman, A.; Nawaz, A.A. Electric vehicles and key adaptation challenges and prospects in Pakistan: A comprehensive review. J. Clean. Prod. 2021, 278, 123375. [CrossRef]

7. Ahmed, W.; Ansari, H.; Khan, B.; Ullah, Z.; Ali, S.M.; Mehmood, C.A.; Qureshi, M.B.; Hussain, I.; Jawad, M.; Khan, M.U.S.; et al. Machine Learning Based Energy Management Model for Smart Grid and Renewable Energy Districts. IEEE Access 2020, 8 , 185059-185078. [CrossRef]

8. Yahaya, A.S.; Javaid, N.; Javed, M.U.; Shafiq, M.; Khan, W.Z.; Aalsalem, M.Y. Blockchain-Based Energy Trading and Load Balancing Using Contract Theory and Reputation in a Smart Community. IEEE Access 2020, 8, 222168-222186. [CrossRef]

9. Masaud, T.M.; Warner, J.; El-Saadany, E.F. A Blockchain-Enabled Decentralized Energy Trading Mechanism for Islanded Networked Microgrids. IEEE Access 2020, 8, 211291-211302. [CrossRef]

10. Ahl, A.; Yarime, M.; Tanaka, K.; Sagawa, D. Review of blockchain-based distributed energy: Implications for institutional development. Renew. Sustain. Energy Rev. 2019, 107, 200-211. [CrossRef]

11. Musleh, A.S.; Yao, G.; Muyeen, S.M. Blockchain Applications in Smart Grid-Review and Frameworks. IEEE Access 2019, 7, 86746-86757. [CrossRef]

12. Siano, P.; Marco, G.D.; Rolan, A.; Loia, V. A Survey and Evaluation of the Potentials of Distributed Ledger Technology for Peer-to-Peer Transactive Energy Exchanges in Local Energy Markets. IEEE Syst. J. 2019, 13, 3454-3466. [CrossRef]

13. SolarCoin. Available online: https://solarcoin.org/wp-content/uploads/SolarCoin_Policy_Paper_EN-1.pdf (accessed on 23 February 2021).

14. Wang, S.; Taha, A.F.; Wang, J.; Kvaternik, K.; Hahn, A. Energy Crowdsourcing and Peer-to-Peer Energy Trading in BlockchainEnabled Smart Grids. IEEE Trans. Syst. ManCybern. Syst. 2019, 49, 1612-1623. [CrossRef]

15. Noor, S.; Yang, W.; Guo, M.; Dam, K.H.V.; Wang, X. Energy Demand Side Management within micro-grid networks enhanced by blockchain. Appl. Energy 2018, 228, 1385-1398. [CrossRef]

16. Kim, G.; Park, J.; Ryou, J. A Study on Utilization of Blockchain for Electricity Trading in Microgrid. In Proceedings of the 2018 IEEE International Conference on Big Data and Smart Computing (BigComp), Shanghai, China, 15-17 January 2018. 
17. Mengelkamp, E.; Notheisen, B.; Beer, C.; Dauer, D.; Weinhardt, C. A blockchain-based smart grid: Towards sustainable local energy markets. Comput. Sci. Res. Dev. 2017, 33, 207-214. [CrossRef]

18. Gai, K.; Wu, Y.; Zhu, L.; Qiu, M.; Shen, M. Privacy-Preserving Energy Trading Using Consortium Blockchain in Smart Grid. IEEE Trans. Ind. Inform. 2019, 15, 3548-3558. [CrossRef]

19. Pop, C.; Cioara, T.; Antal, M.; Anghel, I.; Salomie, I.; Bertoncini, M. Blockchain Based Decentralized Management of Demand Response Programs in Smart Energy Grids. Sensors 2018, 18, 162. [CrossRef] [PubMed]

20. Sikorski, J.J.; Haughton, J.; Kraft, M. Blockchain technology in the chemical industry: Machine-to-machine electricity market. Appl. Energy 2017, 195, 234-246. [CrossRef]

21. Mylrea, M.E.; Gourisetti, S.N.G. Blockchain for smart grid resilience: Exchanging distributed energy at speed, scale and security. In Proceedings of the Resilience Week (RWS 2017), Wilmington, DE, USA, 18-22 September 2017.

22. P. by S. D. 05/07/2020, "Peak \& Off-Peak Electricity Times: Tariffs \& Rates," Canstar Blue, 07-Apr-2021. [Online]. Available online: https:/ / www.canstarblue.com.au/electricity/peak-off-peak-electricity-times (accessed on 23 February 2021).

23. AEMOINEM data dashboard. Available online: https://aemo.com.au/Energy-systems/Electricity/National-Electricity-MarketNEM/Data-NEM/Data-Dashboard-NEM (accessed on 26 February 2020).

24. Solarcoin Price, SLR Price Index, Chart, and Info I CoinGecko. Available online: https://www.coingecko.com/en/coins/solarcoin (accessed on 23 February 2021).

25. Frankenfield, J. Smart Contracts: What You Need to Know. Available online: https://www.investopedia.com/terms/s / smartcontracts.asp (accessed on 23 February 2021).

26. Lokeshgupta, B.; Sivasubramani, S. Multi-objective home energy management with battery energy storage systems. Sustain. Cities Soc. 2019, 47, 101458. [CrossRef]

27. Hussain, I.; Ali, S.; Khan, B.; Ullah, Z.; Mehmood, C.; Jawad, M.; Farid, U.; Haider, A. Stochastic Wind Energy Management Model within smart grid framework: A joint Bi-directional Service Level Agreement (SLA) between smart grid and Wind Energy District Prosumers. Renew. Energy 2019, 134, 1017-1033. [CrossRef]

28. Available online: https:/ / pvoutput.org/live.jsp (accessed on 23 February 2020).

29. Miskelly, A. Wind Energy. Available online: https:/ / anero.id/energy/wind-energy (accessed on 23 March 2020).

30. Nemweb Market Data. Available online: http:/ / www.nemweb.com.au/ (accessed on 23 March 2020).

31. Weather in Australia. Available online: https://www.australia.com/en/facts-and-planning/weather-in-australia.html (accessed on 23 March 2020).

32. Rpc.com.au. 2020. Available online: https://www.rpc.com.au/pdf/Solar_Radiation_Figures.pdf (accessed on 23 March 2020).

33. WeatherSpark.com. Available online: https://weatherspark.com/y/144671/Average-Weather-in-Brisbane-Australia-YearRound (accessed on 23 March 2020). 